\title{
Local, Regional, or Global Asset Pricing?
}

Fabian Hollstein (D)

Leibniz University Hannover School of Economics and Management

hollstein@fcm.uni-hannover.de (corresponding author)

\begin{abstract}
Analyzing several developed and emerging international markets, I test the ability of global, regional, and local models to explain a large set of 134 cross-sectional anomalies. My main finding is that both global and regional factor models create substantially larger average absolute alphas than local factor models. Annual (absolute) anomaly portfolio alphas are on average 1.7 and 1.1 percentage points higher, respectively, with global and regional than with local factor models. Even for the most recent period, there is no evidence of a catch-up of global and regional factor models. There is substantial potential for international diversification of anomaly strategies.
\end{abstract}

\section{Introduction}

There is still a debate in the literature as to whether global, regional, or local factor models are more useful in international cross-sectional asset pricing. The theoretical literature focuses mainly on global asset pricing models (e.g., Solnik (1974), Grauer, Litzenberger, and Stehle (1976), Sercu (1980), and Stulz (1981)). The empirical findings of, for example, Fama and French (1998), Brooks and Del Negro (2005), and Hau (2011) also underline the importance of cross-country components of asset pricing factor models. On the other hand, the results of, among others, Griffin (2002) and Hou, Karolyi, and Kho (2011) support local rather than global pricing.

In the current article, I step into this debate. The main contribution of my article is a detailed analysis of whether global, regional, or local factor models best characterize the cross section of international stock returns. I use a very comprehensive data set, which covers the 48 Morgan Stanley Capital International (MSCI) developed and emerging markets. For each country, I obtain up to 134 cross-sectional anomalies. This large set of anomaly portfolios corresponds to what investors in the different countries might reasonably invest in. Finally, I also examine a wide array of cross-sectional factor models. I create global, regional, and local versions for each of the factor models and analyze which class of models best explains the anomaly portfolio returns.

The key questions underlying my analysis are as follows: Are there systematic differences between the alphas for global, regional, and local factor models? Hence,

I thank Hendrik Bessembinder (the editor) and an anonymous referee for comments that helped greatly improve this article. All remaining errors are my own. This article was funded by the Deutsche Forschungsgemeinschaft (DFG) (project number 433352673). I also thank the Hannover Center for Finance e.V. for partly funding the Datastream and Worldscope databases. 
do alphas depend on the systematic risks an investor is exposed to? Are anomaly alphas different for globally and regionally diversified investors than for local investors? How much alpha would portfolio managers claim if they used the different classes of models? Answers to these questions are important for portfolio managers, investors, and academics alike. For an adequate evaluation, it is essential for investors to isolate the alpha of any strategy. Thus, it is important to document the sensitivity of the alpha measures to the factors used. Each investor may need to choose the type of factor model that is appropriate for him or her.

I address these questions by using time-series tests for all anomaly-quintile portfolios. From these tests, I obtain the average absolute alphas. My first main finding is that global factor models strongly underperform their local counterparts in explaining anomaly returns. On average, a portfolio manager who uses global benchmarks would claim an alpha that is 1.7 percentage points higher per annum than what the manager could claim when using local factor models. Conversely, a globally diversified investor can earn substantially higher abnormal returns than local investors can. Global factor models yield higher absolute alphas than their local counterparts for all the models examined. The differences in (absolute) performance between global and local factor models are larger on average for emerging markets ( 2.5 percentage points on average) but also exceed 1.0 percentage points on average for developed markets. More importantly, local factor models outperform global factor models in all except for one of the individual country cross sections.

While also rejecting global asset pricing models, an important strand of the literature follows the approach of Fama and French (2012), (2017) and analyzes international asset prices at the regional level. An implicit assumption underlying this procedure is that financial markets are regionally integrated, in that regional factor models can price local assets in the different countries. ${ }^{1}$ Therefore, I also examine the performance of regional models for explaining the anomaly portfolio returns. I find that these fare not much better than their global peers. Using regional models, the average absolute alphas of the anomaly portfolios are 1.1 percentage points higher per year than when using local models. Thus, my results also reject regional asset pricing.

Next, I perform factor-spanning regressions. With this approach, I can test whether global and regional factor models can explain the local factors. My results also reject the spanning hypothesis for both global and regional models: Local factors generate sizable alphas when regressed on regional and global factor models.

These results indicate that anomaly investors likely benefit from international diversification of their strategies. Indeed, I find that the average international correlations at the anomaly-category level are moderate at most, indicating a large potential for diversification. Importantly, global and regional factor models account for only part (typically not more than half) of the average anomaly-strategy correlations across countries. Thus, global and regional factors miss a substantial fraction of the international comovement in anomaly-strategy returns.

\footnotetext{
${ }^{1}$ Put differently, investment opportunities (i.e., alphas of different strategies) are similar for local and regionally diversified investors.
} 
In a further step, I examine the time-trends in global, regional, and local factor alphas. In recent years, product markets have become more globalized, and capital markets have arguably become increasingly open. One might expect that these developments would lead to a decrease in the alpha differences. Using 100-month rolling windows to determine the factor alphas, however, I detect no evidence of a catch-up of the global and regional to the local models.

Finally, I examine the relation of average absolute anomaly alpha differences of global and local models with capital controls and political-risk variables. Traditionally, one would associate these variables with the integration of a local financial market into world markets (Karolyi and Stulz (2003), Cooper, Sercu, and Vanpée (2013)). I find that there is some relation between capital controls, political risk, and the size of the local capital markets with the alpha differences of global, regional, and local models. However, this relation appears to be restricted to the countries with the least open, most risky, and smallest capital markets. There is little difference between the medium and highly open countries and so forth. Thus, direct and indirect barriers to capital investing do not serve to explain the differential performance of global, regional, and local factor models.

However, these results do not necessarily imply that financial markets are not globally or regionally integrated. Previous studies show that investors have preferred habitats (e.g., French and Poterba (1991)). On an international level, such preferred habitats in local stock markets can create comovement limited to these markets (Barberis, Shleifer, and Wurgler (2005)). This purely local comovement naturally cannot be captured by broader, global or regional, factor models.

This article adds to several strands of the literature. First, I address the debate on whether global, regional, or local models best describe the cross section of stock returns. In more detail, Fama and French (1998) detect a large international component in countries' value returns and advocate the use of a global factor model. Brooks and Del Negro (2005) show that in the Heston and Rouwenhorst (1995) model, regional factors capture a large part of the information contained in country factors. Hau (2011) uses a natural experiment based on a major MSCI benchmark index recomposition and shows that stocks are priced globally rather than locally. On the other hand, using a sample that includes the United States and 3 big global economies, Griffin (2002) shows that the country-specific Fama and French (1993) factors generally outperform their global counterparts. Hou et al. (2011) compare local and global empirical asset pricing models that include size, value, and momentum factors and find that, for a set of 7 examined anomalies, local models typically provide lower pricing errors than global models.

Based on the results of Brooks and Del Negro (2005), one might advocate regional instead of global factor models when pricing local assets. Fama and French (2012), (2017) examine the cross-section of stock returns of different regions. Subsequent studies often use the same region definition to conduct their tests. Among these is Karolyi and $\mathrm{Wu}$ (2018), who show that global impacts in the form of externality factors are important for a region's asset prices. I contribute to the debate outlined in the first paragraph (including these more subtle points) with a comprehensive analysis of global, regional, and local asset pricing models for a wide range of anomaly variables and factor models. Using a broad set of anomaly portfolio strategies that investors might invest in, I am able to thoroughly analyze the basic 
question underlying this debate. I find that local factor models yield substantially lower pricing errors on average.

This article also adds to the literature on time trends in asset pricing. Petzev, Schrimpf, and Wagner (2016) compare the performance of local and global versions of the capital asset pricing model (CAPM) as well as the Fama and French (1993) and Carhart (1997) models over time for explaining size, book-to-market, and momentum portfolios and a sample that consists mainly of developed markets. The authors find that the explanatory power (in terms of $R^{2}$ ) of global factor models has increased strongly in recent years. However, they do not observe such a catchup in pricing errors. Drawing from my large set of countries, test assets, and factor models, I can shed further light on the latter issue. I show that there is not a catch-up in average absolute alphas in either developed or emerging markets. Additionally, even when using the best among the regional and global models at each point in time, the observation is still the same: Local models price the anomaly portfolios significantly better than their global and regional counterparts throughout my sample period.

The remainder of the article is organized as follows: Section II introduces the data and presents summary statistics. I examine the ability of factor models to explain various anomalies in Section III. In Section IV, I present the results of spanning regressions. I analyze the anomaly correlations in Section V, time trends in the relative model performance in Section VI, and the relation of the alpha differences with traditional measures of financial market integration in Section VII. I use Section VIII to draw conclusions.

\section{Data and Summary Statistics}

\section{A. Data}

My primary data set includes the stock returns of all MSCI developed and emerging markets. In total, my data set comprises the cross sections of 48 different countries. Equity price and market capitalization data are from Datastream. Accounting data are from Worldscope. ${ }^{2}$ I include stocks traded at the countries' respective major exchanges, which are defined as the exchanges on which the majority of stocks are traded (Lee (2011)). ${ }^{3}$ The data span the period from Jan. 1990 to Dec. 2017 , including a total of 7,457 trading days. ${ }^{4,5}$

\footnotetext{
${ }^{2}$ Worldscope makes use of standard data definitions for financial accounting items, attempting to minimize differences in treatment and accounting terminology. See the "Thomson Reuters Worldscope Fundamentals" document for further details.

${ }^{3}$ Most countries have a single major exchange, whereas there are two for Canada (Toronto Stock Exchange (TSX) and TSX Venture), China (Shenzen and Shanghai), Germany (Frankfurt and Xetra), India (BSE Ltd. and National India), Japan (Osaka and Tokyo), South Korea (Korea and KOSDAQ), and the United Arab Emirates (Abu Dhabi and Dubai Financial Market) and three for the United States (American Stock Exchange (AMEX), New York Stock Exchange (NYSE), and NASDAQ).

${ }^{4}$ As in Fama and French (2012), (2017), I choose 1990 as a starting date. This is mainly motivated by the fact that Worldscope added many firms to the database during the late 1980s but did not backfill the historical data for these firms ((Hou et al. (2011)).

${ }^{5}$ In order to be able to start directly in Jan. 1990, I use data prior to Jan. 1990 to create factors and variables if these data are available (and necessary).
} 
In this article, I calculate all returns in U.S. dollars. Thus, I take the perspective of an investor that is unhedged in exchange rates. ${ }^{6}$ Before calculating returns, I convert the total return indices from Datastream into U.S. dollars using the corresponding exchange rates. For the risk-free rate, I use data on the 1-month U.S. Treasury bill yield from Kenneth French's website.

Following Lesmond (2005) and Lee (2011), I include all listed and delisted companies provided in the Datastream database and exclude depositary receipts, real estate investment trusts, and preferred stocks. In doing so, I apply the filters described in Appendix B, Tables B.1 and B.2, of Griffin, Kelly and Nardari (2010). I include only major securities and primary quotes. As in Hou et al. (2011) and Lee (2011), I exclude anomalous observations. More specifically, if the current or past return, $r_{t}$ or $r_{t-1}$, is higher than $100 \%$ and $\left(1+r_{t}\right)\left(1+r_{t-1}\right)-1<20 \%$, both $r_{t}$ and $r_{t-1}$ are set as missing. Furthermore, following Griffin et al. (2010), I set any daily return greater than $200 \%$ as missing. To further limit the effect of outlier observations, I winsorize daily return observations at the $1 \%$ and $99 \%$ levels each day. Moreover, I require a minimum number of return observations per trading day. If more than $90 \%$ of the stocks have 0 returns (in local currency) on a day, the day is declared as nontrading day and is dropped from the analysis (see, e.g., Amihud (2002), Lesmond (2005), and Lee (2011)). I handle delistings, following Ince and Porter (2006), by setting all observations from the end of the sample period to the first nonzero domestic return as missing.

I use the following region definitions, which are based primarily on those of Fama and French (2012), augmented with MSCI emerging markets economies: i) Asia Pacific (Australia, China, Hong Kong, India, Indonesia, Malaysia, New Zealand, Philippines, Singapore, South Africa, South Korea, Taiwan, and Thailand), ii) Europe (Austria, Belgium, Czech Republic, Denmark, Finland, France, Germany, Greece, Hungary, Ireland, Israel, Italy, Netherlands, Norway, Poland, Portugal, Russia, Spain, Sweden, Switzerland, and the United Kingdom), iii) Japan, iv) the Middle East (Egypt, Pakistan, Qatar, Saudi Arabia, Turkey, and the United Arab Emirates), v) North America (Canada, Mexico, and the United States), and vi) South America (Brazil, Chile, Colombia, and Peru). ${ }^{7}$

\section{B. Summary Statistics}

Table 1 presents the summary statistics for each country and the different regions. In total, I have data on 58,348 stocks. For the regions Asia Pacific, Europe, Japan, and North America, the cross sections are large, with well over 2,000 stocks on average. For the Middle East and South America, the cross sections are smaller. Reflecting this reduced size, as indicated in the rightmost column of the table, the factor time series for these two regions do not start before Dec. $1997 .{ }^{8}$ Naturally, for the individual countries, the cross-sections are substantially smaller. However, for

\footnotetext{
${ }^{6}$ Reporting all portfolio returns in U.S. dollars ensures their comparability across countries.

${ }^{7}$ In cases where the allocation is not straightforward, I base it on the trade statistics provided by the World Bank.

${ }^{8}$ I only include a region or country in the analysis if data on all factors of the main factor models are available. To generate the factors, I require at least 30 stocks with valid observations for all sorting variables ((Titman, Wei, and Xie (2013)).
} 
TABLE 1

Summary Statistics

Table 1 presents summary statistics for the regions and countries. NO_FIRMS is the total number of firms in the sample. AVG_NO_FIRMS, MIN_NO_FIRMS, and MAX_NO_FIRMS denote the average, minimum, and maximum number of firms available per month, respectively. AVG_RET is the time-series average of the annualized value-weighted average U.S. dollar market return (in percentage points). "Std. Dev.," "Skew.," and "Kurt." denote the time-series average cross-sectional standard deviation, skewness, and kurtosis, respectively. AVG_MC is the time-series average of the cross-sectional mean market capitalization of the firms (in millions of U.S. dollars). FIRST_OBS indicates the year and monh in which the data for the respective country start, and FIRST_OBS_ presents the first date for which data on all the main factor models are available.

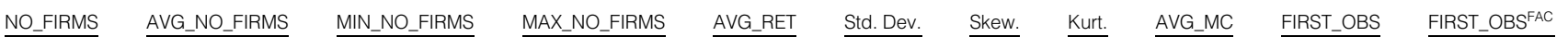

\begin{tabular}{|c|c|c|c|c|c|c|c|c|c|c|c|}
\hline World & 58,348 & 24,065 & 13,351 & 29,886 & 7.90 & 60.2 & 2.08 & 19.0 & 1,227 & Jan. 1990 & Jan. 1990 \\
\hline Asia Pacific & 19,127 & 8,211 & 2,126 & 13,435 & 7.50 & 61.9 & 1.97 & 17.0 & 547 & Jan. 1990 & Jan. 1990 \\
\hline Australia & 3,209 & 1,203 & 519 & 1,706 & 11.2 & 67.9 & 1.82 & 14.7 & 479 & Jan. 1990 & Dec. 1991 \\
\hline China & 3,340 & 1,237 & 6 & 3,247 & 18.3 & 38.9 & 1.38 & 12.7 & 981 & Feb. 1991 & Dec. 2000 \\
\hline Hong Kong & 1,783 & 751 & 183 & 1,556 & 14.1 & 57.8 & 1.79 & 15.7 & 954 & Jan. 1990 & Dec. 1991 \\
\hline India & 2,307 & 968 & 3 & 1,450 & 6.69 & 71.9 & 1.79 & 12.4 & 13 & Jan. 1990 & Dec. 1998 \\
\hline Indonesia & 594 & 286 & 64 & 467 & 8.66 & 56.3 & 1.79 & 15.5 & 437 & May. 1990 & Dec. 1997 \\
\hline Malaysia & 982 & 589 & 182 & 776 & 10.5 & 41.8 & 1.85 & 19.9 & 332 & Jan. 1990 & Dec. 1991 \\
\hline New Zealand & 298 & 107 & 73 & 131 & 12.5 & 48.7 & 1.04 & 13.6 & 263 & Jan. 1990 & Dec. 2000 \\
\hline Philippines & 248 & 152 & 39 & 193 & 7.57 & 55.7 & 1.95 & 15.5 & 383 & Jan. 1990 & Dec. 1997 \\
\hline Singapore & 743 & 362 & 104 & 552 & 9.62 & 43.4 & 1.47 & 14.5 & 534 & Jan. 1990 & Dec. 1991 \\
\hline South Africa & 885 & 341 & 80 & 512 & 11.2 & 55.8 & 1.78 & 16.9 & 889 & Jan. 1990 & Dec. 1991 \\
\hline South Korea & 2,837 & 1,268 & 580 & 1,877 & 8.49 & 58.1 & 1.48 & 14.8 & 366 & Jan. 1990 & Dec. 1994 \\
\hline Taiwan & 1,073 & 592 & 159 & 894 & 6.64 & 39.0 & 1.38 & 13.1 & 736 & Jan. 1990 & Dec. 1997 \\
\hline Thailand & 828 & 407 & 165 & 608 & 9.86 & 46.9 & 1.71 & 15.2 & 325 & Jan. 1990 & Dec. 1997 \\
\hline Europe & 14,673 & 5,591 & 3,575 & 6,827 & 9.15 & 51.6 & 1.81 & 21.0 & 1,384 & Jan. 1990 & Jan. 1990 \\
\hline Austria & 168 & 74 & 38 & 103 & 8.28 & 38.7 & 0.43 & 11.2 & 835 & Jan. 1990 & Dec. 1995 \\
\hline Belgium & 235 & 117 & 68 & 155 & 8.94 & 35.8 & 1.06 & 14.5 & 1,431 & Jan. 1990 & Dec. 1993 \\
\hline Czech Republic & 250 & 68 & 9 & 236 & 12.8 & 43.5 & 0.97 & 8.16 & 1,232 & Jul. 1993 & Jul. 2003 \\
\hline Denmark & 353 & 174 & 122 & 216 & 12.0 & 37.9 & 1.06 & 15.5 & 888 & Jan. 1990 & Dec. 1994 \\
\hline Finland & 221 & 106 & 31 & 139 & 12.9 & 37.4 & 0.89 & 10.1 & 1,171 & Jan. 1990 & Dec. 1995 \\
\hline France & 1,658 & 711 & 305 & 928 & 9.58 & 48.1 & 1.94 & 21.9 & 1,648 & Jan. 1990 & Jan. 1990 \\
\hline Germany & 1,371 & 592 & 294 & 895 & 8.65 & 50.7 & 1.60 & 18.2 & 1,701 & Jan. 1990 & Dec. 1990 \\
\hline Greece & 379 & 210 & 65 & 308 & 6.86 & 54.3 & 1.45 & 12.0 & 272 & Jan. 1990 & Dec. 1996 \\
\hline Hungary & 94 & 34 & 2 & 49 & 12.4 & 52.9 & 0.58 & 7.81 & 340 & Feb. 1991 & Jul. 2010 \\
\hline Ireland & 80 & 39 & 27 & 52 & 7.75 & 48.2 & 0.59 & 7.30 & 1,623 & Jan. 1990 & Jul. 2001 \\
\hline Israel & 680 & 376 & 114 & 490 & 4.74 & 50.9 & 1.09 & 15.3 & 227 & Jan. 1990 & Dec. 2004 \\
\hline Italy & 536 & 221 & 123 & 294 & 7.09 & 34.5 & 1.25 & 14.0 & 1,941 & Jan. 1990 & Dec. 1992 \\
\hline Netherlands & 238 & 122 & 82 & 183 & 10.4 & 36.7 & 0.56 & 12.3 & 3,671 & Jan. 1990 & Dec. 1992 \\
\hline Norway & 573 & 165 & 91 & 224 & 11.6 & 48.9 & 0.99 & 10.7 & 774 & Jan. 1990 & Dec. 1993 \\
\hline Poland & 1,037 & 308 & 3 & 787 & 14.7 & 56.0 & 1.20 & 10.4 & 220 & May. 1991 & Jul. 2002 \\
\hline Portugal & 138 & 68 & 40 & 110 & 5.56 & 48.8 & 0.98 & 13.1 & 514 & Jan. 1990 & Jul. 1996 \\
\hline
\end{tabular}

(continued on next page) 
TABLE 1 (continued)

Summary Statistics

\begin{tabular}{|c|c|c|c|c|c|c|c|c|c|c|c|}
\hline & NO_FIRMS & AVG_NO_FIRMS & MIN_NO_FIRMS & MAX_NO_FIRMS & AVG_RET & Std. Dev. & Skew. & Kurt. & AVG_MC & FIRST_OBS & FIRST_OBSFAC \\
\hline Russia & 323 & 125 & $\frac{2}{2}$ & 253 & 21.6 & $\overline{58.5}$ & $\overline{1.34}$ & $\overline{12.7}$ & 2,560 & $\overline{\text { Oct. } 1995}$ & Dec. 2009 \\
\hline Spain & 322 & 141 & 90 & 173 & 9.91 & 34.2 & 1.06 & 14.4 & 3,217 & Jan. 1990 & Dec. 1993 \\
\hline Sweden & 1,113 & 300 & 128 & 547 & 12.2 & 53.3 & 1.18 & 12.6 & 904 & Jan. 1990 & Dec. 1992 \\
\hline Switzerland & 378 & 208 & 179 & 236 & 11.3 & 32.4 & 0.70 & 16.3 & 3,832 & Jan. 1990 & Dec. 1990 \\
\hline United Kingdom & 4,526 & 1,482 & 1,246 & 1,826 & 8.97 & 52.4 & 1.51 & 17.8 & 1,481 & Jan. 1990 & Jan. 1990 \\
\hline Japan & 3,624 & 2,398 & 1,703 & 2,738 & 3.17 & 37.0 & 1.96 & 23.7 & 1,450 & Jan. 1990 & Jan. 1990 \\
\hline Middle East & 1,325 & 664 & 4 & 1,048 & 12.9 & 53.5 & 1.95 & 16.3 & 533 & Jan. 1990 & Dec. 1997 \\
\hline Egypt & 176 & 98 & 3 & 141 & 6.41 & 45.8 & 1.36 & 11.6 & 348 & Nov. 1994 & Dec. 2008 \\
\hline Pakistan & 351 & 217 & 4 & 276 & 14.5 & 50.6 & 1.79 & 15.4 & 117 & Jan. 1990 & Dec. 1998 \\
\hline Qatar & 44 & 35 & 14 & 41 & 13.3 & 29.0 & 0.77 & 5.45 & 2,771 & Jan. 2004 & - \\
\hline Saudi Arabia & 174 & 93 & 1 & 169 & 13.8 & 33.7 & 0.97 & 8.24 & 3,800 & Dec. 1999 & Dec. 2011 \\
\hline Turkey & 475 & 287 & 145 & 379 & 16.8 & 53.3 & 1.87 & 14.2 & 434 & Jan. 1994 & Dec. 1998 \\
\hline United Arab Emirates & 105 & 85 & 31 & 98 & 12.6 & 40.1 & 1.31 & 10.9 & 1,551 & Jan. 2004 & Dec. 2011 \\
\hline North America & 18,623 & 6,772 & 5,814 & 7,581 & 11.1 & 67.4 & 2.02 & 16.8 & 1,995 & Jan. 1990 & Jan. 1990 \\
\hline Canada & 6,932 & 2,529 & 1,873 & 2,905 & 10.0 & 87.4 & 1.84 & 11.8 & 307 & Jan. 1990 & Jan. 1990 \\
\hline Mexico & 170 & 60 & 39 & 82 & 12.8 & 38.7 & 0.91 & 10.3 & 865 & Jan. 1990 & Dec. 2000 \\
\hline United States & 11,521 & 4,183 & 3,716 & 4,868 & 11.2 & 50.2 & 1.74 & 19.9 & 3,080 & Jan. 1990 & Jan. 1990 \\
\hline South America & 976 & 430 & 121 & 520 & 8.45 & 48.6 & 2.29 & 26.0 & 1,026 & Jan. 1990 & Dec. 1997 \\
\hline Brazil & 333 & 125 & 15 & 219 & 16.4 & 52.2 & 1.52 & 15.6 & 1,983 & Jul. 1994 & Dec. 2001 \\
\hline Chile & 278 & 170 & 121 & 196 & 13.3 & 36.6 & 1.52 & 20.1 & 731 & Jan. 1990 & Dec. 1997 \\
\hline Colombia & 115 & 52 & 23 & 70 & 11.6 & 35.8 & 0.74 & 12.2 & 1,277 & Feb. 1992 & Dec. 2011 \\
\hline Peru & 250 & 111 & 20 & 133 & -3.67 & 52.2 & 1.44 & 17.8 & 587 & Feb. 1991 & Dec. 2005 \\
\hline
\end{tabular}


the vast majority of countries, I have data on more than 100 stocks, which should enable the creation of sufficiently diversified portfolios. For most developed markets and part of the emerging markets, the factor time series start in the early 1990s. On the other hand, the cross section of Qatar is too small throughout the sample period.

The annual value-weighted market returns for individual countries range between $-3.7 \%$ for Peru and $21.6 \%$ for Russia. For most countries, these are between $7 \%$ and $13 \%$. For the regions, it ranges between $3 \%$ and $14 \%$ per annum. Among the regions, the market return is lowest for Japan, which suffered from weak economic performance during most of my sample period. In contrast, I observe the highest average market return of $11 \%$ per annum for North America.

\section{Factor Models}

For the main analysis, I consider the following factor models: i) the CAPM, ii) the Fama and French (1993) 3-factor model (FF-3), iii) the Carhart (1997) 4-factor model (C-4), iv) the Fama and French (2015) 5-factor model (FF-5), v) the Hou, Xue and Zhang (2015) 4-factor model (HXZ-4), vi) the Hou, Mo, Xue and Zhang (2021) 5-factor model (HMXZ-5), and vii) the Stambaugh and Yuan (2017) 4-factor model (SY-4). Detailed descriptions of the factor models are in Section OA1 of the Supplementary Material.

\section{Explaining Anomalies}

The first pillar of my analysis of global, regional, and local factor models is a test for whether, and to what degree, these can explain the returns of anomaly portfolios. The main questions I want to answer in this section are as follows: Are there systematic differences between the alphas for global, regional, and local factor models? How much alpha would portfolio managers additionally claim if they used different classes of models?

\section{A. Methodology}

I use a set of 134 anomaly variables. The anomaly selection and definition are based mainly on Hou et al. (2015) and Green, Hand, and Zhang (2017). I have to perform minor adjustments to some of the anomalies for the international data set. In addition, I add a few (recent) anomalies not contained in those lists. The anomalies belong to 6 different categories: i) momentum, ii) value versus growth, iii) investment, iv) profitability, v) intangibles, and vi) trading frictions. For most anomaly variables, I build 5 value-weighted portfolios based on break points derived from big stocks (those in the top $90 \%$ of cumulative market capitalization). This study design, with value-weighted portfolios and break points from big stocks, mitigates the impact of micro-cap stocks, which are difficult to trade in practice. Detailed definitions of the anomaly variables, as well as further details on the procedure, are provided in Section OA2 of the Supplementary Material.

For each anomaly portfolio $j$, I regress the time series of monthly portfolio excess returns on that of the different global, regional, and local factor models, as follows: 


$$
r_{j, t}-r_{f, t}=\alpha_{j}+\beta_{j}^{\prime} f_{t}^{\mathrm{GLOB} / \mathrm{REG} / \mathrm{LOC}}+\varepsilon_{j, t},
$$

where $r_{j, t}$ denotes the return during month $t$ of the anomaly portfolio, and $r_{f, t}$ is the risk-free rate over the corresponding period. $\alpha_{j}$ is the intercept (alpha), $\beta_{j}$ is a $k \times 1$ vector of factor sensitivities, and $f_{t}^{\mathrm{GLOB} / \mathrm{REG} / \mathrm{LOC}}$ is a $k \times 1$ vector that contains the returns of all $k$ factors of a global, regional, or local factor model at time $t$. $\varepsilon_{j, t}$ is the regression residual. To run the regression in equation (1), I require a minimum of 100 time-series observations. The main tests are based on the average absolute alphas of the different portfolios for the different models.

\section{B. Aggregate Results}

Figure 1 visualizes the main results (the corresponding numbers and significance tests can be found in Table 2). The (equally weighted) aggregated absolute alphas are reported. The aggregation scheme proceeds as follows: First alphas are averaged across all portfolios of an anomaly, then over the up to 134 anomalies within a country, and finally across countries. On average, I have data on 122 anomalies per country. The average absolute annualized return per anomaly portfolio and country amounts to $8.87 \%$. Global factor models can explain approximately half of this return on average. For example, for the CAPM, the average absolute annualized alpha amounts to $4.73 \%$. Other models perform better than the CAPM, though. The best-performing global model is the C-4 model, which leaves an average absolute alpha of $4.25 \%$ per annum.

Regional models perform somewhat better. The average absolute annualized alphas are up to 1 percentage point lower than those for the global factor models. The regional CAPM and C-4 models yield average absolute alphas of $4.30 \%$ and $4.01 \%$ per annum, respectively. These results are consistent with Fama and French (2012), who find that global factor models do not perform well for explaining regional portfolios sorted on size, book-to-market, and momentum.

However, Fama and French (2012) stop at the regional level and do not examine local factor models. I find that for all factor models, the local versions of the models clearly perform best. For the CAPM and C-4 models, the local average absolute annualized alphas amount to $3.12 \%$ and $2.76 \%$, respectively.

Thus, for globally and regionally diversified investors, anomaly portfolio alphas are substantially larger than those for purely local investors. Portfolio managers who use global or regional rather than local factor models would claim alphas of substantially larger magnitudes. For the Carhart (1997) C-4 model, which is commonly used in portfolio evaluation, the differences between absolute local and global or regional factor model alphas amount to 1.49 and 1.25 percentage points, respectively, per annum on average. ${ }^{9}$ For other factor models, in many instances, the differences are even larger. For all models, the differences in alphas

\footnotetext{
${ }^{9}$ Because the focus is on absolute alphas, the alphas of the global and regional models could both be larger (mainly if the alpha of the portfolio is positive) or smaller (primarily for negative alphas). Because it is at the discretion of the investor whether to go long or short in a portfolio, the magnitude of the alphas is of primary importance.
} 
FIGURE 1

\section{Factor Alpha Summary}

Figure 1 plots the average absolute annualized alphas (in percentage points) of all anomaly quintile portfolios for different factor models. For each anomaly portfolio, equation (1) is estimated for each of the global, regional, and local factor models (see Section OA1 of the Supplementary Material for the definition of the factor model acronyms). The (equally weighted) aggregated absolute alphas are reported. The aggregation scheme proceeds as follows: First, absolute alphas are averaged across all the portfolios of an anomaly, then over all 134 anomalies within a country, and finally across countries. The black bar denotes alphas toward the global version of the factor models. The dark-gray and light-gray bars present the alphas toward the regional and local factor models, respectively. The average absolute returns for the different graphs are $8.87 \%$ (all countries), $8.06 \%$ (developed markets), and $9.81 \%$ (emerging markets).
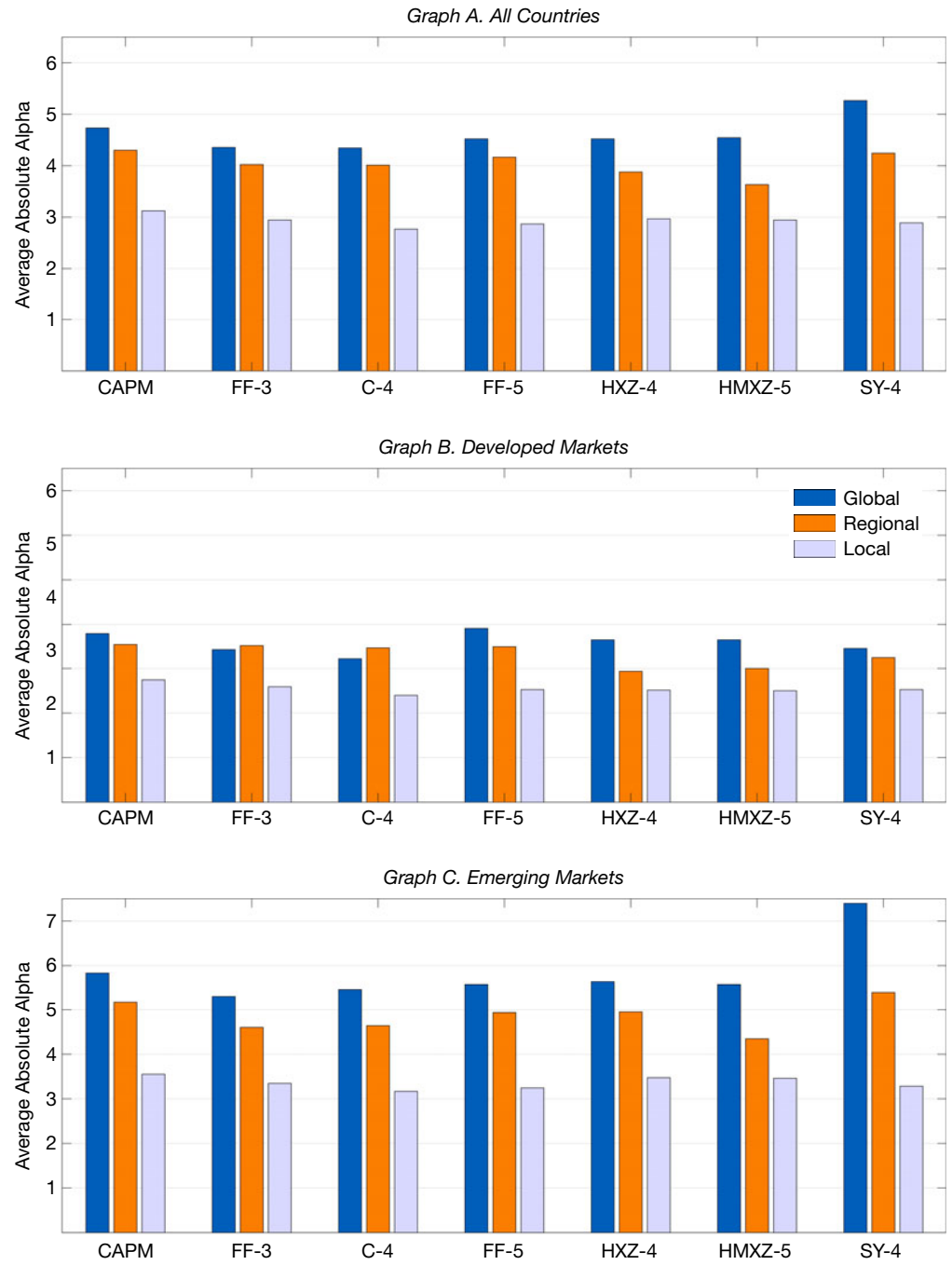

between local and global as well as regional factor models are highly statistically significant.

One possibility is that the aggregate results are driven by emerging markets, whose market integration might be lagging behind that of developed markets. To account for this possibility, I split the sample into a part that only includes developed 
TABLE 2

\section{Explaining Anomalies}

Table 2 compares the performance of several global, regional, and local factor models in explaining portfolio returns sorted by different anomaly variables. Panel A presents average results across all countries. In addition, I present panels that consider developed markets (Panel B) and emerging markets separately (Panel C). For each anomaly portfolio in each country, equation (1) is estimated for each of the global, regional,

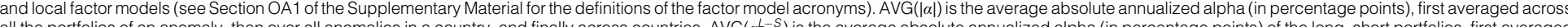
all the portfolios of an anomaly, then over all anomalies in a country, and finally across countries. AVG $\left(\alpha^{L-S}\right)$ is the average absolute annualized alpha (in percentage points) of the long-short portfolios, first averaged over all anomalies in a country and then across countries. $\Delta|\alpha|$ and $\Delta \alpha^{L}-s$ present the differences in the average alphas for different factor model specifications (global, regional, local). To test whether these differences are statistically significant, I use the double-clustered (by country and anomaly) standard errors of Cameron, Gelbach, and Miller (2011) applied to all anomaly-country observations. *, ** and ${ }^{* * *}$ indicate statistical significance at the $10 \%, 5 \%$, and $1 \%$ levels, respectively.

$$
\frac{\text { Global }}{\underline{\operatorname{AVG}(|\alpha|)} \quad \underline{\operatorname{AVG}\left(\alpha^{L-S}\right)}}
$$

Panel A. All Countries

\begin{tabular}{ll}
\hline No. of obs. & 122 \\
RET & 8.87 \\
CAPM & 4.73 \\
FF-3 & 4.30 \\
C-4 & 4.25 \\
FF-5 & 4.68 \\
HXZ-4 & 4.57 \\
HMXZ-5 & 4.53 \\
SY-4 & 5.28
\end{tabular}

Panel B. Developed Markets

\begin{tabular}{|c|c|c|c|c|}
\hline No. of obs. & 122 & 120 & 122 & 120 \\
\hline RET & 8.06 & 4.28 & 8.06 & 4.28 \\
\hline CAPM & 3.78 & 4.89 & 3.54 & 4.88 \\
\hline FF-3 & 3.43 & 4.97 & 3.51 & 5.02 \\
\hline C- 4 & 3.22 & 4.42 & 3.46 & 4.27 \\
\hline FF-5 & 3.90 & 4.96 & 3.50 & 4.71 \\
\hline HXZ-4 & 3.65 & 4.57 & 2.95 & 4.22 \\
\hline HMXZ-5 & 3.64 & 4.53 & 3.00 & 4.17 \\
\hline SY-4 & 3.46 & 4.33 & 3.25 & 4.22 \\
\hline
\end{tabular}

$\frac{\text { Local }}{\underline{\operatorname{AVG}(|\alpha|)} \quad \underline{\operatorname{AVG}\left(\alpha^{L-S}\right)}}$

120
5.00
5.41
5.53
5.15
5.59
5.33
5.32
5.15

$\frac{\text { Regional }}{\underline{\operatorname{AVG}(|\alpha|)} \quad \underline{\operatorname{AVG}\left(\alpha^{L-S}\right)}}$

$\begin{array}{ll}122 & 120 \\ 8.87 & 5.00 \\ 4.30 & 5.40 \\ 4.02 & 5.61 \\ 4.01 & 5.07 \\ 4.17 & 5.36 \\ 3.88 & 5.02 \\ 3.63 & 4.96 \\ 4.24 & 5.12\end{array}$

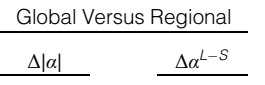

$\begin{array}{ll}122 & 120 \\ 8.87 & 5.00 \\ 3.12 & 5.48 \\ 2.94 & 5.26 \\ 2.76 & 4.56 \\ 2.87 & 4.77 \\ 2.97 & 4.91 \\ 2.95 & 4.82 \\ 2.88 & 4.52\end{array}$

122
8.06
2.75
2.60
2.40
2.53
2.52
2.50
2.53

$\begin{array}{lr}0.00 & 0.00 \\ 0.43^{* * *} & 0.01 \\ 0.28 & -0.08 \\ 0.24 & 0.08 \\ 0.51 & 0.23^{* *} \\ 0.70^{*+*} & 0.31^{* * *} \\ 0.91^{* * *} & 0.35^{* * *} \\ 1.04^{* *+} & 0.03\end{array}$

120
4.28
4.96
4.72
3.90
4.18
4.28
4.19
3.87

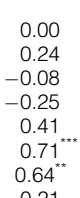

0.00
0.01
-0.05
0.15
$0.25^{* * *}$
$0.35^{* * *}$
$0.36^{* *}$
0.10

Global Versus Local

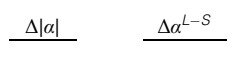

$\Delta \alpha^{L-S}$

$0.00^{* * *}$
$1.61^{* * *}$
$1.35^{* * *}$
$1.49^{* * x}$
$1.81^{* * *}$
$1.61^{* * *}$
$1.59^{* * * *}$
$2.40^{* * *}$

0.00
-0.07
$0.27^{* * *}$
$0.59^{* * *}$
$0.81^{* * *}$
$0.42^{* * *}$
$0.49^{* * *}$
$0.63^{* * *}$

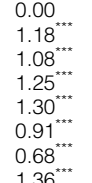

0.00

$0.34^{* * *}$

$0.51^{* * *+}$

$0.58^{* * *}$

0.10

0.14

$0.60^{*+*+}$

0.00
$1.03^{* * *}$
$0.83^{* * *}$
$0.81^{* * *}$
$1.37^{* * *}$
$1.13^{* * *}$
$1.14^{* * *}$
$0.92^{* * *}$

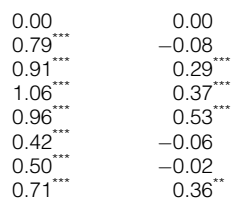

(continued on next page) 
TABLE 2 (continued)

\section{Explaining Anomalies}

\begin{tabular}{|c|c|c|c|c|c|c|c|c|c|c|c|c|}
\hline & \multicolumn{2}{|c|}{ Global } & \multicolumn{2}{|c|}{ Regional } & \multicolumn{2}{|c|}{ Local } & \multicolumn{2}{|c|}{ Global Versus Regional } & \multicolumn{2}{|c|}{ Global Versus Local } & \multicolumn{2}{|c|}{ Regional Versus Local } \\
\hline & $\underline{\operatorname{AVG}(|\alpha|)}$ & $\underline{\operatorname{AVG}\left(\alpha^{L-S}\right)}$ & $\underline{\operatorname{AVG}(|\alpha|)}$ & $\underline{\operatorname{AVG}\left(\alpha^{L-S}\right)}$ & $\underline{\operatorname{AVG}(|\alpha|)}$ & $\underline{\operatorname{AVG}\left(\alpha^{L-S}\right)}$ & $\Delta|\alpha|$ & $\Delta \alpha^{L-S}$ & $\Delta|\alpha|$ & $\Delta \alpha^{L-S}$ & $\Delta|\alpha|$ & $\Delta \alpha^{L-S}$ \\
\hline \multicolumn{13}{|c|}{ Panel C. Emerging Markets } \\
\hline No. of obs. & 122 & 120 & 122 & 120 & 122 & 120 & & & & & & \\
\hline RET & 9.81 & 5.83 & 9.81 & 5.83 & 9.81 & 5.83 & 0.00 & 0.00 & 0.00 & 0.00 & 0.00 & 0.00 \\
\hline CAPM & 5.83 & 6.01 & 5.17 & 6.00 & 3.55 & 6.08 & $0.66^{* *}$ & 0.02 & $2.28^{* * *}$ & -0.07 & $1.62^{* * *}$ & -0.09 \\
\hline FF-3 & 5.30 & 6.18 & 4.61 & 6.29 & 3.34 & 5.88 & 0.69 & -0.11 & $1.95^{* * *}$ & 0.29 & $1.26^{* * *}$ & $0.40^{*}$ \\
\hline C-4 & 5.45 & 6.00 & 4.65 & 6.01 & 3.17 & 5.33 & 0.80 & -0.00 & $2.28^{* * *}$ & $0.67^{* * *}$ & $1.48^{* * *}$ & $0.67^{* *}$ \\
\hline FF-5 & 5.57 & 6.31 & 4.95 & 6.11 & 3.25 & 5.47 & 0.62 & 0.20 & $2.32^{* * *}$ & $0.84^{* * *}$ & $1.70^{* * *}$ & $0.64^{* *}$ \\
\hline HXZ-4 & 5.64 & 6.21 & 4.96 & 5.95 & 3.48 & 5.65 & 0.68 & 0.27 & $2.16^{* * *}$ & $0.56^{* * *}$ & $1.48^{* * t}$ & 0.29 \\
\hline HMXZ-5 & 5.57 & 6.23 & 4.36 & 5.89 & 3.46 & 5.56 & $1.21^{* * *+}$ & $0.35^{*}$ & $2.11^{* * *}$ & $0.67^{* * *}$ & $0.90^{* *}$ & 0.33 \\
\hline SY-4 & 7.40 & 6.11 & 5.39 & 6.16 & 3.29 & 5.28 & $2.01^{* *}$ & -0.04 & $4.11^{* * *}$ & $0.83^{* * *}$ & $2.10^{* * * t}$ & $0.87^{* * *}$ \\
\hline
\end{tabular}


markets and one that only includes emerging markets. The main results hold for both developed and emerging markets. The differences in alphas are somewhat smaller for developed markets than for emerging markets on average but are still in the range of approximately 1.0 percentage points per annum. For emerging markets, the differences between the average absolute annualized alphas of global and local models are close to 2 percentage points. For all models, the differences in average absolute alphas between local and global or regional factor models are statistically significant.

\section{Disaggregated Results}

In the next step, I examine the performance of global, regional, and local factor models separately for each country. The relative performance of global, regional, and local factor models could be strongly heterogeneous. It is, for example, possible that European countries that have largely implemented the open-market provisions of the European Union are more strongly financially integrated among each other and in global markets compared with more isolated countries in other regions. Increased financial integration could be associated with a better relative performance of global and regional factor models.

I present the results in Figures 2 and 3, and Table A1 of the Supplementary Material presents more detailed numbers and significance tests at the regional level. ${ }^{10}$ The (equally weighted) aggregated absolute alphas are reported. The aggregation scheme proceeds as follows: First, alphas are averaged across all portfolios of an anomaly, then over all 134 anomalies within a country, and finally over the main factor models. Indeed, I find that there are differences across countries. However, the common theme is that local factor models explain anomaly portfolio returns better than global and regional factor models.

Comparing the ability of global and local models to explain the anomaly portfolio returns, in Figure 2, I find that in all countries except for Ireland, the average alphas toward the global factor models are higher than those toward the local factor models. The differences are also economically large for many important developed markets, for example, 1.5 percentage points for Hong Kong, 0.6 percentage points for Germany, 0.5 percentage points for the United Kingdom, 1.6 percentage points for Japan, and 2.2 percentage points for the United States. Among developed markets, it is visible that the difference in performance between global and local factor models is relatively smaller for countries perceived as particularly open, such as France, Germany, the Netherlands, Switzerland, and the United Kingdom. On the other hand, the substantial difference in performance between the global and local factor models for the United States might be surprising at first glance because, by most measures, the United States should be well integrated into global financial markets.

\footnotetext{
${ }^{10}$ For Figures 2 and 3 , the average global, regional, and local factor alphas are averaged across all the main factor models. As an alternative, Figures A1 and A2 of the Supplementary Material present the results when picking the respective best among the global, regional, and local factor models. Although the differences between the classes of factor models are somewhat less strongly pronounced, the main patterns in these figures are similar to those presented here.
} 


\section{FIGURE 2}

\section{Factor Alpha Summary: Global Versus Local}

Figure 2 plots the average absolute annualized returns and alphas (in percentage points) of all anomaly quintile portfolios for each country. For each anomaly portfolio, equation (1) is estimated for each of the global and local factor models. The (equally weighted) aggregated absolute alphas are reported. The aggregation scheme proceeds as follows: First, absolute alphas are averaged across all the portfolios of an anomaly, then over all 134 anomalies within a country, and finally over the main factor models. The light-gray bar presents the average absolute alpha of the local versions of the factor models. The dark-gray bar indicates the additional average absolute alpha when using global factor models. The average absolute return is the sum of the light-gray, dark-gray, and white bars. If the dark-gray (white) bar is in the negative area, it means that the global absolute alphas (absolute returns) are on average lower than the local absolute alphas (global absolute alphas).
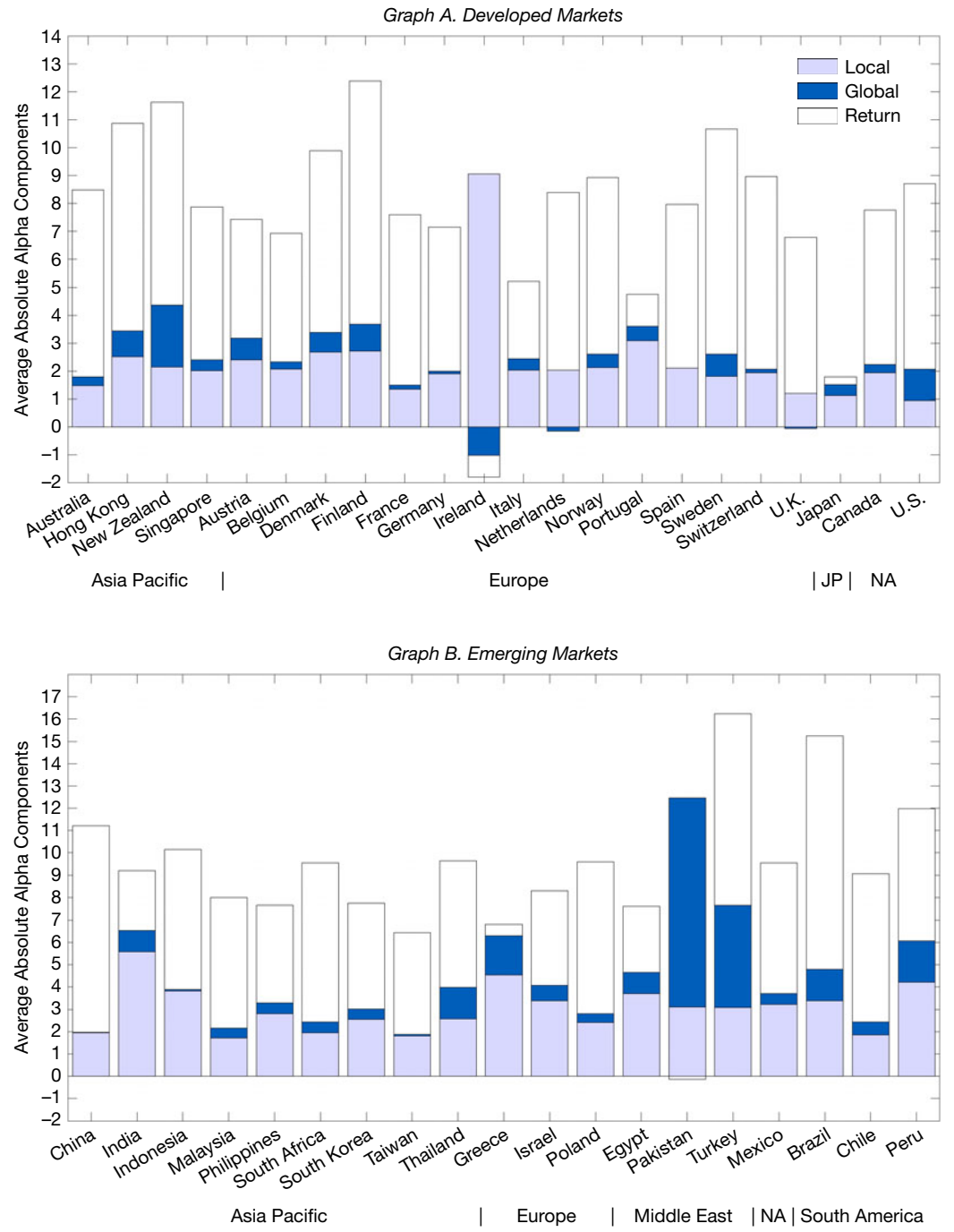

Consistent with my previous results, the lower part of Figure 2 shows that the differences in performance between the global and local factor models are substantially larger in emerging markets. For example, for China, the difference in average annualized absolute alphas amounts to 0.9 percentage points, and for South Korea, 


\section{FIGURE 3}

\section{Factor Alpha Summary: Regional Versus Local}

Figure 3 plots the average absolute annualized returns and alphas (in percentage points) of all anomaly quintile portfolios for each country. For each anomaly portfolio, equation (1) is estimated for each of the regional and local factor models. The (equally weighted) aggregated absolute alphas are reported. The aggregation scheme proceeds as follows: First, absolute alphas are averaged across all the portfolios of an anomaly, then over all 134 anomalies within a country, and finally over the main factor models. The light-gray bar presents the average absolute alpha of the local versions of the factor models. The medium-gray bar indicates the additional average absolute alpha when using regional factor models. The average absolute return is the sum of the light-gray, medium-gray, and white bars. If the medium-gray (white) bar is in the negative area, it means that the regional absolute alphas (absolute returns) are on average lower than the local absolute alphas (global absolute alphas).
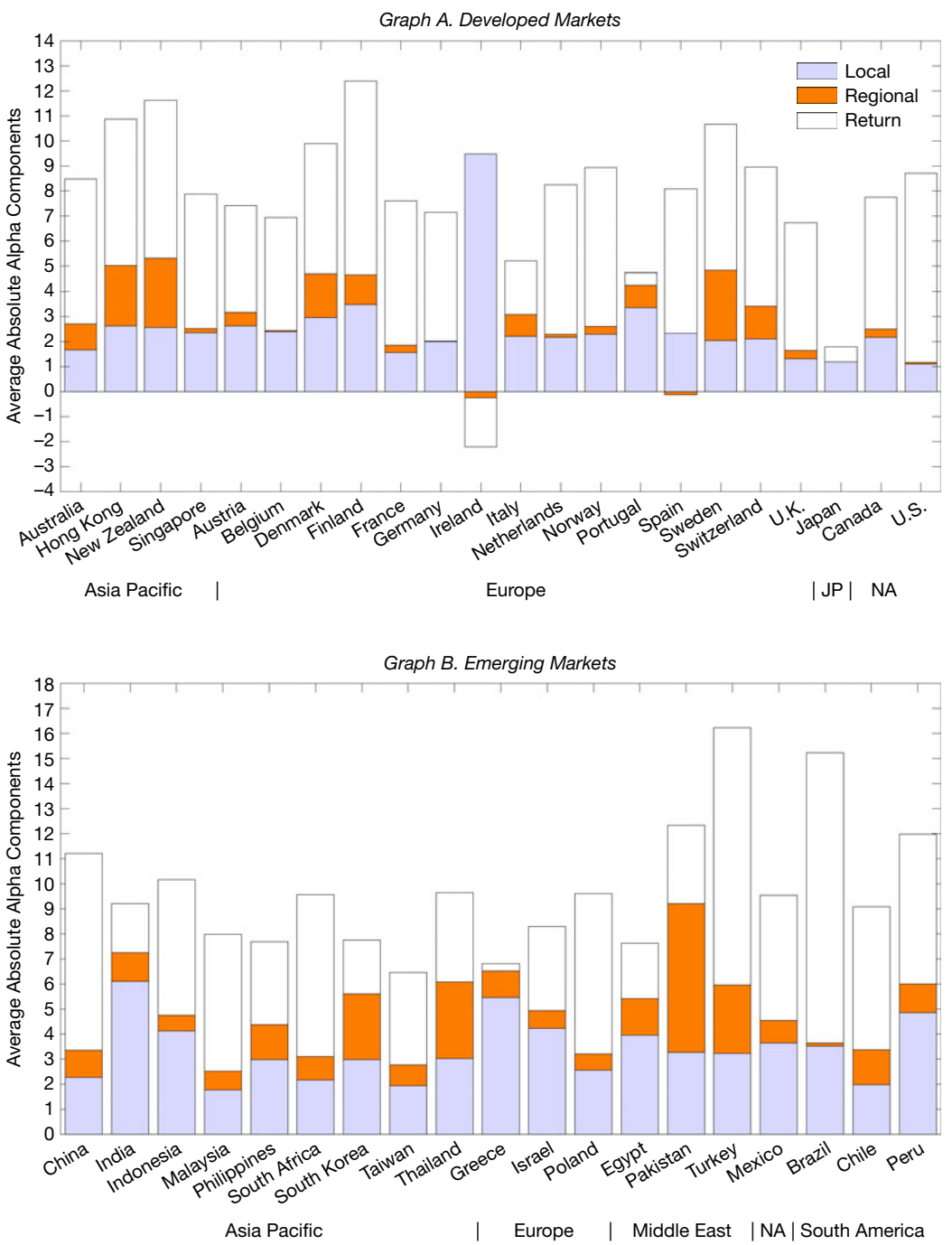

it amounts to 2.5 percentage points, but the differences can also be huge, such as 10.6 percentage points for Pakistan and Turkey.

For all countries except for Ireland, Spain, and Israel, the differences between the average absolute alphas of the global and local factor models are statistically 
significant toward the $1 \%$ level (results untabulated). For Spain, these differences are statistically significant toward the $5 \%$ level.

Figure 3 further presents the average differences between the regional and local factor alphas for the anomalies. These results are similar to those for the comparison of the global and local factor models. The average absolute alphas toward the regional factor models are significantly higher than those for the local factor models for all countries except for Ireland, Germany, and Spain. The magnitudes of the differences are reduced for some countries, most notably the United States, but are also material for most countries. Thus, the alphas reported by portfolio managers for their international holdings are strongly sensitive to the type of factor models used for performance evaluation. Investors should choose, based on whether they are globally, regionally, or only locally diversified, the suitable class of factor models when evaluating potential investments and the performance of money managers.

Table 3 and Tables A2 and A3 of the Supplementary Material present results that are even further disaggregated. That is, these tables show the results for the

TABLE 3

Anomaly Heat Map: C-4 Model

Table 3 presents a heat map to summarize information about the average absolute alphas of global, regional, and local versions of the Carhart (1997) C-4 factor model for different anomaly categories. At the end of each month and for each anomaly variable, I form value-weighted quintile portfolios based on break points derived from big stocks. I test whether the different global, regional, and local factor models can explain the anomaly long returns. The colors visualize the magnitude of the difference between the average annualized absolute alphas toward global and regional versus those toward local models $\left(|\bar{\alpha}|^{\mathrm{GLOB} / \mathrm{REG}}-|\bar{\alpha}|^{\mathrm{LOC}} ;\right.$ global/regional minus local) within the different anomaly categories.

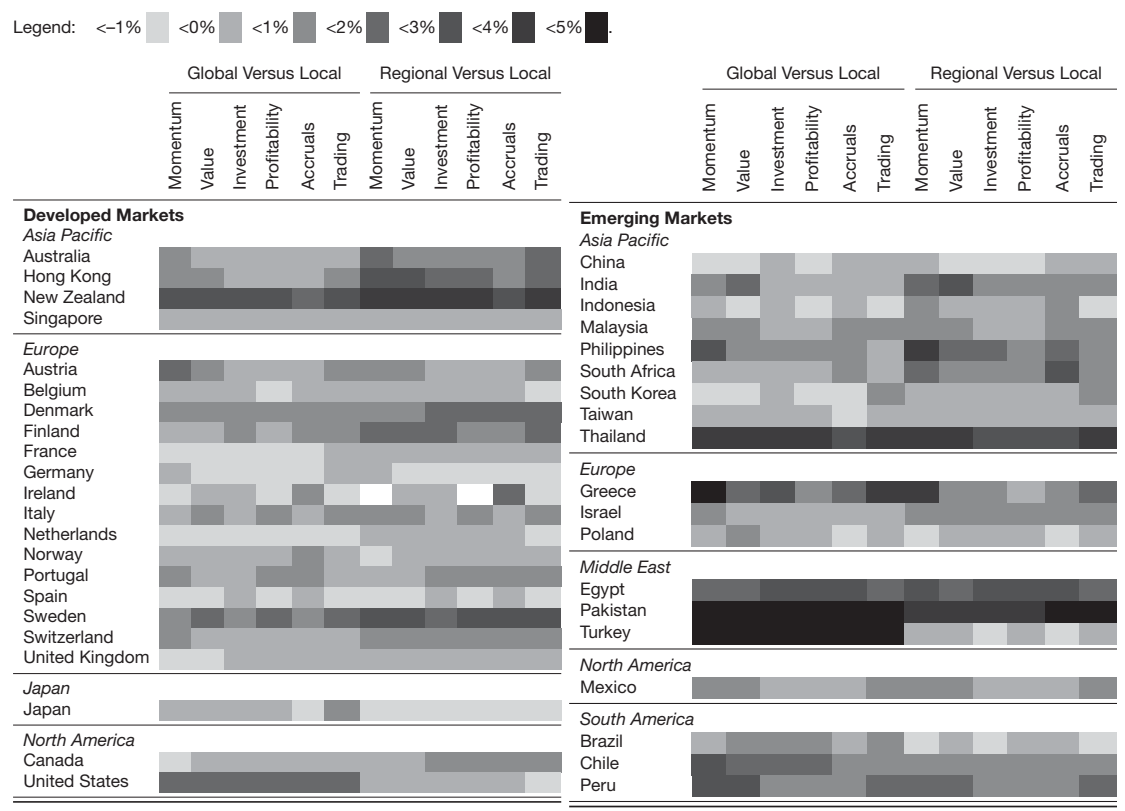


different anomaly categories within the individual countries. For example, for the C-4 model (presented in Table 3), one can see that there are very few countrycategory combinations for which the global or regional models yield lower average absolute alphas than the local models. On the other hand, there are various countrycategory combinations for which the average absolute local alphas are substantially smaller than their global or regional counterparts, with the differences partly far exceeding the average differences.

\section{Robustness}

Although including a large set of factor models, the main part of my analysis still covers only a subset of the models available. It might be that for others, the global or regional versions perform better than their local counterparts. In this section, I thus examine 7 more models in addition to the previous 7: viii) the Carhart (1997) model augmented by Pástor and Stambaugh (2003) liquidity (C-5), ix) the Daniel, Hirshleifer, and Sun (2020) 3-factor model (DHS-3), x) the Barillas and Shanken (2018) 6-factor model (BS-6), xi) the Fama and French (2018) 5-factor model with a cash profitability factor (FF-5 ${ }^{\mathrm{CASH}}$ ), xii) the Fama and French (2018) 6-factor model (FF-6), xiii) the Hou et al. (2011) 3-factor model (HKK-3), and xiv) the Zhang (2006) 4-factor model (Z-4). Models viii-xii have been studied mainly for the United States, whereas Zhang (2006) and Hou et al. (2011) explicitly design their model for international asset markets. I present the results in Figure A3 and Table A4 of the Supplementary Material. For all factor models, the results are qualitatively similar to those of the main models.

Furthermore, Fama and French (2017) caution that sorts based on accounting variables could be affected by regional differences in accounting standards. Although the global standard data definitions of Worldscope should mitigate most of these differences, I also examine the robustness of my results to forming global portfolios based on regional break points. That is, when obtaining global factors, I allocate the stocks based on the accounting-variable break points derived separately for each region. I present the results in Figure A4 and Table A5 of the Supplementary Material. I find that using regional break points does not materially improve the performance of the global factor models.

Finally, I check whether adding foreign components to local factor models further boosts their performance. This analysis is similar in spirit (although different in the empirical details) to the partial segmentation approach of Karolyi and $\mathrm{Wu}$ (2018), as well as earlier tests in Griffin and Stulz (2001) and Hou et al. (2011). I start with the local factor models and expand the model using the equivalent foreign global and foreign regional factors (global and regional factors that exclude a certain country). If foreign components matter for local asset prices, I expect the average absolute alphas to be substantially smaller for the local-plus-foreign model specifications than for the purely local model.

I present the results in Table A6 of the Supplementary Material. I find that the improvements when adding foreign factor components are very modest. In some cases, the average absolute alphas of the anomaly portfolios are even higher with than without the foreign components. These results contrast with Hou et al. (2011) and Karolyi and $\mathrm{Wu}$ (2018). Hou et al. (2011) find that "foreign components ... are 
as important as local components for pricing" (p. 2530). However, this conclusion is mainly based on the number of rejections of a Gibbons, Ross, and Shanken (1989) (GRS) test statistic for different anomalies. Because the results of such GRS tests can be highly misleading (Fama and French (1996)), in this article, I focus on the average absolute alphas. In Hou et al. (2011), adding foreign factor components also does not serve to materially reduce these.

Karolyi and $\mathrm{Wu}$ (2018) find that models with so-called "externality factors" outperform purely local and global factor models. These externality factors capture foreign components based on local stocks traded in open global markets. The authors find that the models with such foreign components generally yield lower average absolute alphas on a regional level than the purely regional versions of the factor models. Based on a substantially larger set of anomalies, I find that simple foreign factors are of little value beyond the local factor models.

\section{Factor Spanning}

In the next step, in this section, I analyze to what extent global and regional factor models are able to span the factors in the corresponding regional and local models.

\section{A. Methodology}

For each factor of a factor model, I regress its time series on that of the factor model at a broader level. That is, I regress each factor of a local model on those of the corresponding global model as well as (for a separate analysis) the corresponding regional models and each factor of a regional model on those of the corresponding global model. For example, when comparing global and local factor models, I run the following regression for each factor:

$$
f_{j, t}^{\mathrm{LOC}}=\alpha_{j}+\beta_{j}^{\prime} f_{t}^{\mathrm{GLOB}}+\varepsilon_{j, t}
$$

where $f_{j, t}^{\mathrm{LOC}}$ is one of the $k$ factors of a local model. All other variables are as previously defined. Again, I require a minimum of 100 time-series observations.

For each factor model, I save the average absolute factor return, the average absolute alpha, and the average adjusted $R^{2}$ of the regressions. In addition, I test the hypothesis that the alphas of all factors with respect to the broader factor model are jointly 0 . For this purpose, I use the GRS test, which is described in Section OA3 of the Supplementary Material.

\section{B. Main Results}

I present the main factor-spanning results in Table 4. If the spanning hypothesis is rejected at the $10 \%$ significance level for part of the countries of one category, the GRS test statistic is printed in italic font, and if the hypothesis is rejected for all countries of one category, the GRS test statistic is printed in bold font. As can be seen in the table, there is barely any subcategory of factor model spanning and region combinations for which the GRS test is not printed either in italic or bold font. Thus, global and regional factor models generally cannot explain the average 
TABLE 4

\section{Factor-Spanning Regressions}

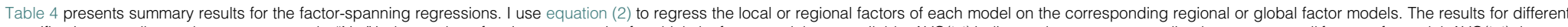

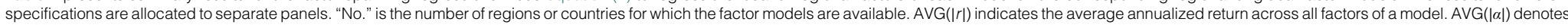

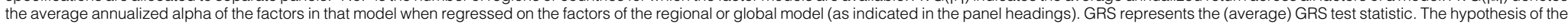

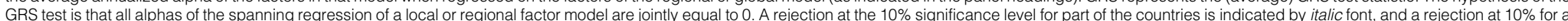

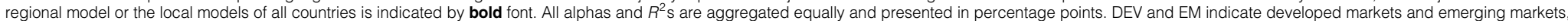
respectively.

\begin{tabular}{|c|c|c|c|c|c|c|c|c|c|c|c|c|c|c|c|c|c|c|c|c|c|c|c|c|c|c|c|}
\hline \multicolumn{5}{|c|}{ CAPM } & \multicolumn{4}{|c|}{ FF-3 } & \multicolumn{4}{|c|}{ C-4 } & \multicolumn{4}{|c|}{ FF-5 } & \multicolumn{4}{|c|}{ HXZ-4 } & \multicolumn{4}{|c|}{ HMXZ-5 } & \multicolumn{3}{|c|}{ SY-4 } \\
\hline No. & $\begin{array}{c}\text { AVG } \\
(|r|)\end{array}$ & $\begin{array}{l}\text { AVG } \\
(|\alpha|)\end{array}$ & GRS & $R^{2}$ & $\begin{array}{c}\text { AVG } \\
(|r|)\end{array}$ & $\begin{array}{c}\text { AVG } \\
(|\alpha|)\end{array}$ & GRS & $R^{2}$ & $\begin{array}{c}\text { AVG } \\
(|r|)\end{array}$ & $\begin{array}{c}\text { AVG } \\
(|\alpha|)\end{array}$ & GRS & $R^{2}$ & $\begin{array}{c}\text { AVG } \\
(|r|)\end{array}$ & $\begin{array}{c}\text { AVG } \\
(|\alpha|)\end{array}$ & GRS & $R^{2}$ & $\begin{array}{c}\text { AVG } \\
(|r|)\end{array}$ & $\begin{array}{l}\text { AVG } \\
(|\alpha|)\end{array}$ & GRS & $R^{2}$ & $\begin{array}{l}\text { AVG } \\
(|r|)\end{array}$ & $\begin{array}{c}\text { AVG } \\
(|\alpha|)\end{array}$ & GRS & $R^{2}$ & $\begin{array}{c}\text { AVG } \\
(|r|)\end{array}$ & $\begin{array}{c}\text { AVG } \\
(|\alpha|)\end{array}$ & GRS \\
\hline
\end{tabular}

Global Versus Regional

Asia Pacific

Europ

Middle East

North America

Sorth America

\section{$\begin{array}{llllll}1 & 5.8 & 0.4 & 0.0 & 64 & 5.2\end{array}$}

$\begin{array}{llll}2.2 & 1.4 & 48 & 6.3\end{array}$

$\begin{array}{lllll}2.6 & 1.4 & 46 & 4.2 & 2.1\end{array}$

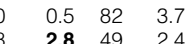

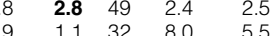

$\begin{array}{lll}1.1 & 32 & 8.0 \\ \mathbf{9 . 1} & 79 & 4.0\end{array}$

$\begin{array}{llll}1.1 & 1.1 & 58 & 5.2 \\ 2.5 & 1.8 & 34 & 1.9\end{array}$

$\begin{array}{llllll}58 & 5.2 & -2.7 & 4.1 & 59 & 2.9\end{array}$

Global Versus Local

Asia Pacific DEV

Asia Pacific EM

Europe DEV

Europe EM

Japan

Middle East

North America DEV

North America EM

South America

Regional Versus Local

\begin{tabular}{|c|c|c|c|c|c|c|c|c|c|c|c|c|c|c|c|c|c|c|c|c|c|c|c|c|c|c|c|c|c|}
\hline Asia Pacific DEV & 4 & 9.5 & 4.0 & 2.1 & 61 & 5.8 & 3.7 & 2.9 & 30 & 7.0 & 5.3 & 5.8 & 28 & 4.7 & 3.5 & 3.5 & 23 & 3.7 & 2.1 & 1.9 & 24 & 3.5 & 2.5 & 1.9 & 21 & 7.5 & 5.0 & 3.7 & 27 \\
\hline Asia Pacific EM & 9 & 8.4 & 2.7 & 0.4 & 44 & 6.9 & 4.1 & 1.6 & 25 & 6.7 & 4.7 & 2.1 & 24 & 5.8 & 4.4 & 2.1 & 23 & 5.5 & 3.6 & 2.0 & 23 & 5.3 & 3.7 & 2.1 & 22 & 7.7 & 5.9 & 2.1 & 23 \\
\hline Europe DEV & 16 & 7.0 & 2.6 & 1.2 & 71 & 4.4 & 3.1 & 1.7 & 42 & 5.9 & 3.8 & 1.7 & 43 & 4.3 & 3.4 & 1.8 & 33 & 4.4 & 2.9 & 1.4 & 31 & 4.2 & 2.9 & 1.3 & 27 & 6.6 & 4.2 & 1.6 & 34 \\
\hline Europe EM & 3 & 11 & 3.6 & 0.9 & 59 & 5.6 & 2.9 & 1.0 & 26 & 6.2 & 3.9 & 1.2 & 27 & 6.1 & 5.0 & 1.9 & 21 & 7.5 & 5.6 & 3.2 & 24 & 7.1 & 5.7 & 3.2 & 20 & 9.9 & 6.3 & 1.9 & 27 \\
\hline Middle East & 2 & 18 & 7.7 & 3.0 & 43 & 9.7 & 3.9 & 2.0 & 35 & 9.3 & 4.5 & 2.3 & 33 & 7.1 & 3.5 & 1.6 & 30 & 8.0 & 5.9 & 3.2 & 28 & 6.7 & 4.8 & 2.6 & 30 & 9.3 & 7.8 & 4.1 & 29 \\
\hline North America DEV & 2 & 7.5 & 0.8 & 1.0 & 83 & 3.8 & 1.2 & 1.9 & 73 & 5.1 & 2.2 & 4.7 & 75 & 3.7 & 1.0 & 1.2 & 70 & 4. & 1. & 0.9 & 67 & 4.3 & 1. & 0.8 & 65 & 6.8 & 2.3 & 2.1 & \\
\hline North America EM & 1 & 12 & 4.7 & 1.4 & 54 & 6.1 & 2.6 & 0.6 & 24 & 7.2 & 5.1 & 1.8 & 22 & 4.5 & 3.0 & 0.9 & 17 & 6.8 & 6.2 & 3.7 & 22 & 5.5 & 4.9 & 2.9 & 19 & 12 & 12 & 6.3 & 2 \\
\hline South America & 3 & 12 & 2.7 & 0.7 & 69 & 7.1 & 2.6 & 1.0 & 42 & 6.9 & 3.1 & 1.4 & 42 & 6.5 & 3.6 & 1.4 & 35 & 7.9 & 4.4 & 2.2 & 32 & 7.8 & 4.5 & 1.9 & 28 & 8.8 & 5.4 & 2.2 & 37 \\
\hline
\end{tabular}


returns of local factors. In the following discussion, I will examine this result in more detail.

The first question I examine is whether global factor models can span regional factor models. The previous section shows that the absolute alphas of regional models for a broad set of anomalies are smaller on average than those of global models. I thus expect that the global factors are generally unable to fully span regional factors.

The results for the comparison between global and regional factor models are in the first panel of Table 4. Starting with the CAPM, I find that the global market excess return has substantial explanatory power for market excess returns of different regions. The $R^{2}$ s are highest for Europe and North America, with $82 \%$ and $79 \%$, respectively, and comparably lowest for Japan and the Middle East, with $49 \%$ and $32 \%$, respectively. For Asia Pacific, Europe, and the Middle East, the global market excess return is able to span the regional market excess returns, whereas the GRS test detects a statistically significant alpha for Japan and North America. One would thus be ill-advised to use a global CAPM for these markets.

For the other factor models, the picture is similar. Although global factor models are able to explain a substantial part of the time-series variation of regional factors on average, at least some of the factors yield substantial alphas. The GRS test rejects the hypothesis that all alphas of regional factors with respect to global factors are jointly 0 for at least 2 of the 6 regions for each model. The GRS test rejects the hypothesis that the global FF-5 model can span its regional counterparts even for 4 out of 6 regions.

The second panel of Table 4 presents the results of factor-spanning regressions of local models by their global counterparts. For this analysis, I split the regions into developed markets (DEV) and a subset of emerging markets (EM). Naturally, given the modest performance for explaining regional models, the global models are also largely unable to explain the factor returns of the local models. The average absolute alphas of the local factors are only rarely substantially smaller than the average absolute local factor returns. In some cases, the average absolute alphas even exceed the average absolute returns. Thus, for the majority of countries, global factor models appear to be unable to fully explain local stock returns. The performance of the global factor models seems to be overall somewhat better in developed markets than in emerging markets. The finding that global factors do not span those in emerging markets is consistent with and updates the early evidence on this issue in Harvey (1995) and Rouwenhorst (1999).

The studies of Fama and French (2012), (2017), among others, combine individual countries into regions and perform all asset pricing tests on a regional level. An implicit assumption of this research design is that financial markets are regionally financially integrated. A very important final question, thus, relates to whether regional factors are able to span local factors.

In the final panel of Table 4, I therefore present the results of the tests of whether regional factor models can span their local counterparts. The $R^{2} \mathrm{~s}$ of the regional factor models are generally somewhat higher than those of the global factor models. Thus, risk factors seem to comove more strongly at the regional level than they do at the global level. The absolute alphas of the local factors are also somewhat smaller on average for the regional factor models than for the global 
factor models. However, in particular for Emerging Markets, these are partially still sizable. Overall, regional factor models also generally fail to span local factor models.

\section{Robustness}

In Table A7 of the Supplementary Material, I present the results for further factor models. These are very similar to those of my main models.

Furthermore, I present the results for regional break points in global factors in Table A8 of the Supplementary Material. The $R^{2} \mathrm{~s}$ for most regions are similar to those of the global factors without regional break points. Interestingly, for Europe, and most strongly pronounced for North America, these are generally higher when using regional break points. However, the average absolute alphas are often even higher when using the global factors with regional break points. Overall, also with regional break points, the global factors fail in spanning regional and local factors.

\section{Can Factor Models Explain Anomaly Correlations?}

The previous sections show that local factor models outperform their global and regional counterparts in explaining anomaly portfolio returns and that the local factor models cannot be spanned by regional and global factor models. Thus, anomaly investments in different countries across the globe seem to be exposed not only to the same global factors but also in part to potentially diversifiable local factor components.

In this section, I thus examine to what extent anomaly investments are correlated across different markets. In a second step, I check whether the global, regional, and local factor models are able to explain the correlations between the different categories of anomalies across countries. For this analysis, I aggregate all anomalies of a certain category (momentum, value, investment, profitability, accruals, and trading) within a country. To gain maximum exposure to an anomaly category, I focus on the long-short returns, defining the long and short sides for each single anomaly based on which of the two extreme portfolios yields higher returns for the full sample in the United States. I weight the long-short returns for each individual anomaly equally when aggregating to a category. Thus, for each category in each country, I have one time series.

Table 5 reports the average pairwise correlations of the anomaly categories across countries. For all countries, the average correlation in momentum-strategy returns amounts to $19.7 \%$, indicating that there is only moderate momentum comovement across countries. ${ }^{11}$ These results suggest that for investors, there is substantial diversification potential when following cross-country momentum strategies. For the value and trading categories, the average pairwise correlations are also moderate at $10.5 \%$ and $22.8 \%$, respectively. The correlations among the investment, profitability, and accruals categories across countries are at an even much smaller scale, with $5.58 \%, 1.85 \%$, and $3.95 \%$, respectively, on average. Thus, for all categories, sizable diversification benefits emerge.

\footnotetext{
${ }^{11}$ For comparison, the average pairwise correlation of the countries' market excess returns amounts to $41.2 \%$ in my sample.
} 
TABLE 5

Anomaly Correlations Across Countries

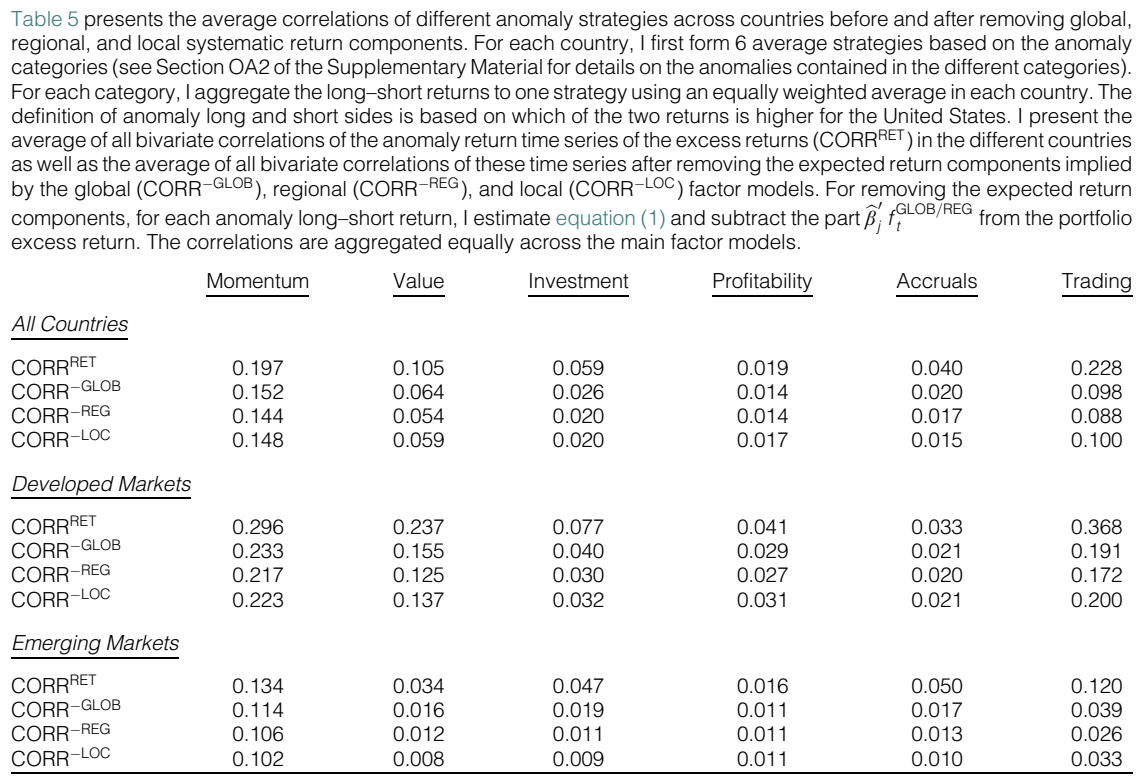

When focusing on developed markets of certain regions only, presented in Table A9 of the Supplementary Material, the average pairwise correlations are somewhat higher, especially in Europe and North America. Nevertheless, the highest correlation in North America (with only Canada and the United States) amounts to only $54.1 \%$. The highest correlation among European developed markets is $43.9 \%$. Both numbers indicate that there is still potential for diversification.

On the other hand, it is important to examine the prevailing correlations in more detail. These could be due to commonalities in fundamentals and/or investor bases; comovement in momentum strategies, for example, across markets may be due to systematic similarities of momentum stocks across markets. In addition, the cause could be global capital investing, where money managers simultaneously invest and divest in momentum strategies across a wide variety of countries.

An important question thus relates to whether the global and regional factor models can account for the correlations. If there are fundamental common movements in these stocks, the global factor models should be able to explain them. To analyze this, I subtract the full-sample systematic return components from the local anomaly-category return time series. That is, for each anomaly long-short return, I estimate equation (1) and subtract the part $\widehat{\beta}_{j}^{\prime} f_{t}^{\mathrm{GLOB} / \mathrm{REG} / \mathrm{LOC}}$ from the portfolio excess return.

Afterward, I examine the average pairwise correlations of these remaining unsystematic return components across countries. When considering all countries, 
I find that for the momentum category, global factors can explain only a little of the average correlation. After removing the systematic components, on average the correlation decreases from $19.7 \%$ to $15.2 \% .^{12}$ Thus, approximately threequarters of the correlation cannot be explained by the factor models. For the value category, about two-thirds of the correlation cannot be explained. For the investment, accruals, and trading categories, the global factor models can explain roughly half of the average pairwise correlations across countries.

The regional models and, naturally, the local models fare not much better than the global models in explaining the average correlations. ${ }^{13}$ When focusing on subsets of the countries, such as, for example, the developed markets of a certain region (in Table A9 of the Supplementary Material), the share of the correlations that can be explained by the global factor models is even smaller in many cases. Thus, there appears to be substantial international comovement in the strategy returns that is not accounted for by the global factor models. Similarly, there is large systematic comovement in anomaly returns across the countries within a region, which is not accounted for by the regional factors.

Finally, in Figure 4, I present the results for 20 (subjectively selected) of the most important anomaly variables while making sure that each anomaly category is represented with at least 2 anomalies. I find that there is much heterogeneity in the average anomaly long-short correlations of these variables. ${ }^{14}$ For $\mathrm{MOM}_{0,6}^{6}$, $\mathrm{MOM}_{0,1}^{12}$, and DISTRESS, the average correlations are highest. On the other hand, for EXPGRWTH, ACCQ, and OPLEV, the anomaly correlations are rather low. The common theme, though, is that the global and regional factor models largely cannot explain the correlations. The systematic factor-related components can explain at most $50 \%$ of the average correlations for most of the anomalies.

\section{Time Trends in Model Performance}

In the period after World War II, there were substantial barriers to crosscountry capital flows. Over time, these barriers have been substantially reduced by a wave of liberalization of financial markets across the globe. Reflecting these changes, as Karolyi and Stulz (2003) note, the home bias of U.S. investors was substantially reduced between the years 1985 and 1994. Although my sample period starts after most of these changes have taken place, it is possible that during the most recent period, financial market integration has increased further. Connected to this, Petzev et al. (2016) argue that global financial markets may have recently become more integrated. It is therefore conceivable that my results are driven by a lack of financial integration for the first part of my sample period and that things are different in more recent times.

\footnotetext{
${ }^{12}$ For comparison, the average pairwise correlation of the countries' market excess returns shrinks from $41.2 \%$ to $8.34 \%$ after subtracting the systematic parts that can be explained by the global market excess return.

${ }^{13}$ The local models are not designed to capture global comovement in a strategy. They can only account for the part of the global comovement that also shows up in the local factors.

${ }^{14}$ The definitions of the anomaly variables can be found in Section OA2 of the Supplementary Material.
} 
FIGURE 4

\section{Anomaly Correlations}

Figure 4 plots the average correlations of selected anomaly strategies across countries before and after removing global and regional systematic return components. I present the average of all bivariate correlations of the anomaly return time series in the different countries as well as the average of all bivariate correlations of these time series after removing the expected return components implied by the global and regional factor models. For removing the expected return components, for each anomaly long-short return, I estimate equation (1) and subtract the part $\widehat{\beta}_{j}^{\prime} f_{t}^{\text {GLOB/REG }}$ from the portfolio excess return. The white bar indicates the average bivariate anomaly correlation. The dark-gray and medium-gray bars indicate the average correlations that result after removing the global and regional systematic return components, respectively. The correlations are aggregated equally across the main factor models. Definitions of the anomaly acronyms can be found in Section OA2 of the Supplementary Material.
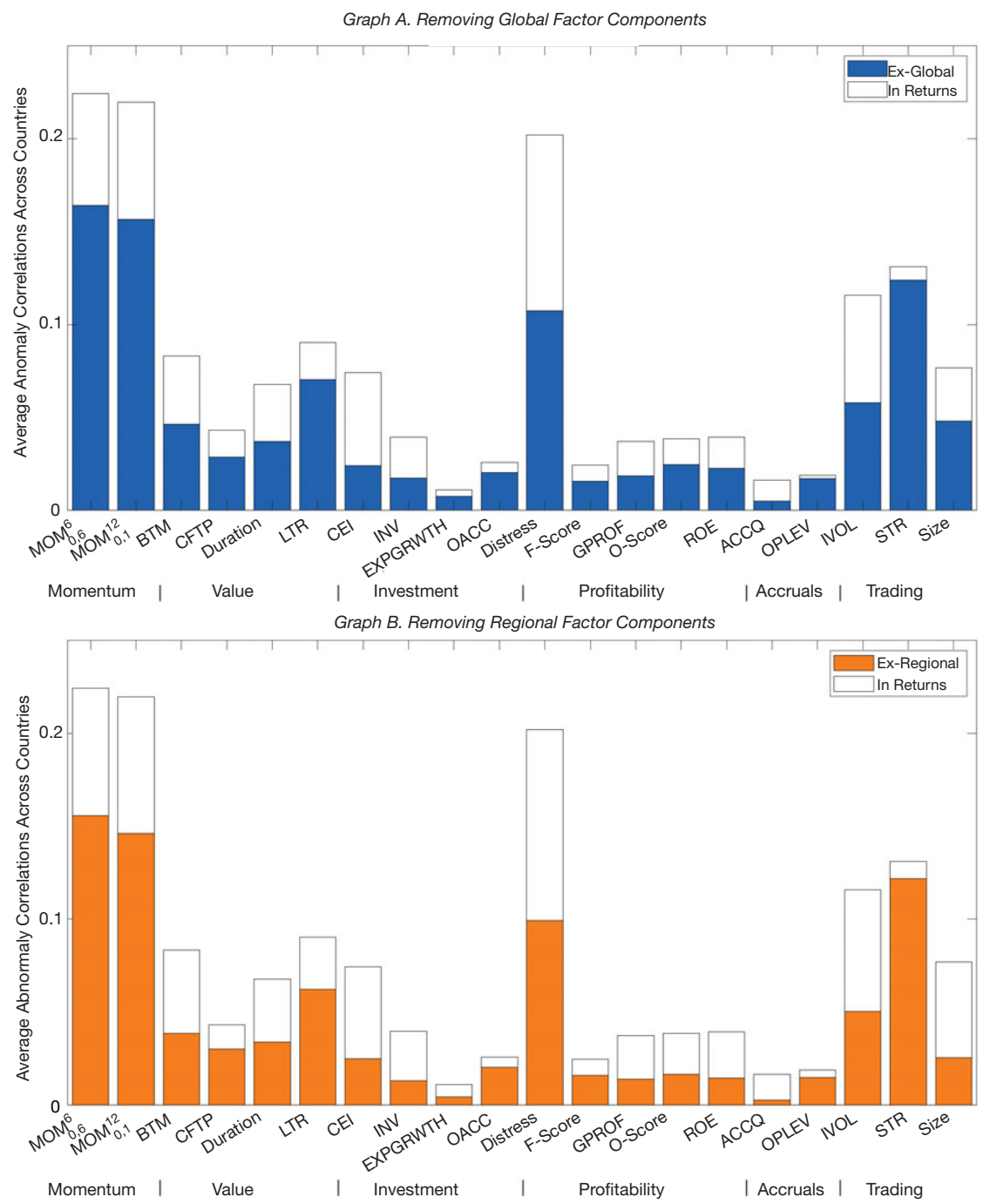

To test for time trends in the model performance, I use 100-month rollingwindow estimates of equation (1). In Figure 5, I present the results. The (equally weighted) aggregated absolute alphas are reported. The aggregation scheme proceeds as follows: First, alphas are averaged across all the portfolios of an anomaly, 


\section{FIGURE 5}

\section{Global, Regional, and Local Alpha Trends}

Figure 5 plots 100-month rolling-window average absolute annualized alphas (in percentage points) for global, regional, and local factor models. For each anomaly portfolio, equation (1) is estimated for each of the global, regional, and local factor models using the past 100 months. The (equally weighted) aggregated absolute alphas are reported. The aggregation scheme proceeds as follows: First, absolute alphas are averaged across all the portfolios of an anomaly, then over all 134 anomalies within a country, then over the main factor models, and finally over the countries indicated in the graph titles. The dark-gray line represents the global factor models, the dashed medium-gray line represents the regional factor models, and the light-gray line represents the local factor models. For the figure, the results are allocated to the end dates of the 100-month windows.
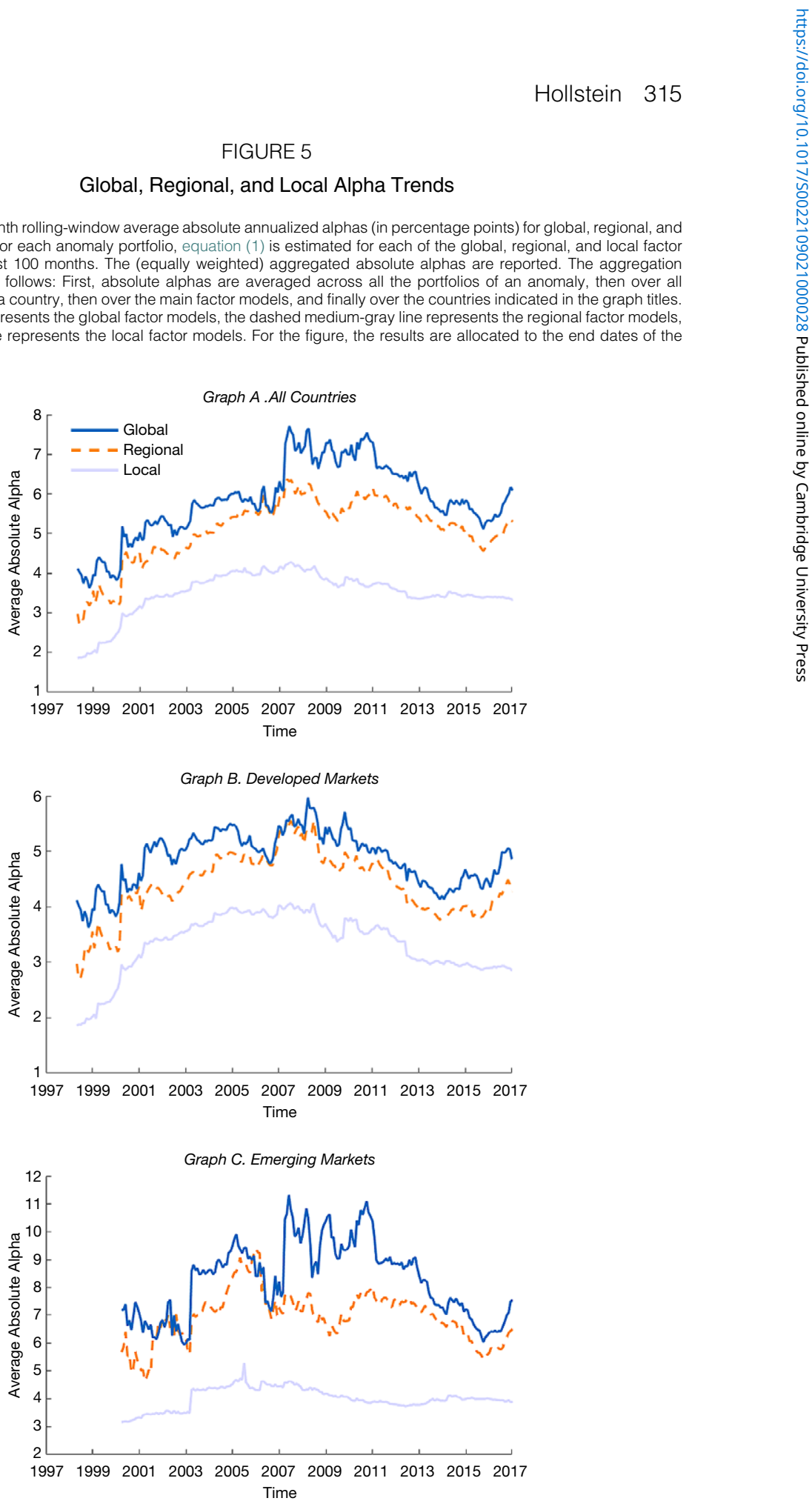
then over all 134 anomalies within a country, then over the main factor models, and finally over the countries indicated in the figure headings. ${ }^{15}$

Throughout the entire sample period, the average absolute global and regional alphas of the anomaly portfolios are substantially higher than those for the local factor models. The average difference between annualized absolute global and local alphas is often 2 percentage points or more. The difference between the average global or regional and local absolute alphas is statistically significant throughout the sample period (untabulated). The regional models explain the average anomaly portfolio returns significantly better than the global models $70 \%$ of the time.

I find that the average absolute alpha levels increase in the first part of the sample as more and more smaller countries enter. Furthermore, I observe a pronounced increase in average global and regional factor alphas around the outset of the 2007 financial crisis. Thus, it seems that the crisis has made asset prices more local. Interestingly, there is another upward spike in the difference between average global and local absolute alphas toward the end of my sample period. The results are similar for developed and emerging markets. Thus, one might wonder what these results imply for the question of how integrated global financial markets are.

\section{Alpha Differences and Financial Market Integration}

The previous sections show that local factor models outperform regional and global factor models when it comes to explaining anomaly portfolio returns. However, I also find that there is substantial heterogeneity across countries regarding the relative performance of global, regional, and local models. Thus, in this section, I examine to what extent differences across countries can be traced back to traditional measures of financial market integration, such as market openness, political risk, and the size of the local stock markets. I measure market openness with the Chinn and Ito (2006) index of financial openness. Higher values imply fewer capital controls and, hence, more market openness. In addition, I examine a political risk rating (the International Country Risk Guide (ICRG); a higher index implies lower risk) and the size of the stock market relative to GDP (market capitalization (MC) to GDP). More detailed definitions of these variables can be found in Section OA4 of the Supplementary Material. As can be seen from Table A10 of the Supplementary Material, these country characteristics are moderately, but far from perfectly, correlated.

I sort the countries into terciles based on each of these measures and examine the average global, regional, and local absolute anomaly portfolio alphas. In Figure 6, I present the results. I find that there is some relation between capital controls and the relative performance of global, regional, and local factor models. For the countries with the least capital controls, I observe the largest differences between the average absolute global and local alphas. However, the effect is mostly restricted to the smallest tercile. There is little difference between terciles 2 and 3.

\footnotetext{
${ }^{15}$ In Figure A5 of the Supplementary Material, I repeat the analysis using only the best models. That is, at each point in time, I pick the respective global, regional, and local model with the lowest average absolute alpha. The results are qualitatively similar.
} 


\section{FIGURE 6}

\section{Global and Regional Versus Local Alphas and Country Characteristics}

Figure 6 plots the average absolute annualized alphas (in percentage points) for the global and local factor models for countries with different characteristics. For each anomaly portfolio, equation (1) is estimated for each of the global, regional, and local factor models (see Section OA1 of the Supplementary Material for the definitions of the factor model acronyms). The (equally weighted) aggregated absolute alphas are reported. The aggregation scheme proceeds as follows: First, absolute alphas are averaged across all the portfolios of an anomaly, then over all 134 anomalies within a country, then across countries. In this final step, the countries are sorted into terciles based on their market openness (Chinn-Ito index), their political risk rating (International Country Risk Guide (ICRG); a higher index implies lower risk), or their average total ratio of stock market capitalization to GDP (see Section OA4 of the Supplementary Material for the definitions of the country characteristics). The light-gray bars present the average absolute alphas of the local versions of the factor models. The dark-gray and medium-gray bars indicate the additional average absolute alphas when using the global and regional factor models, respectively.

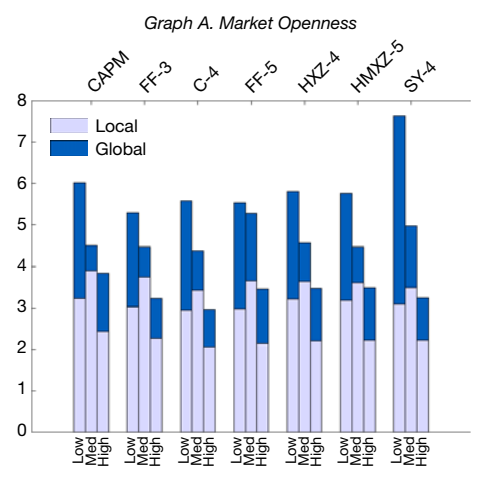

Graph C. MC to GDP

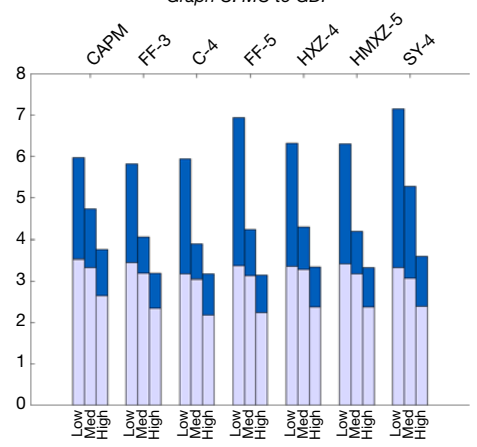

Graph E. ICRG

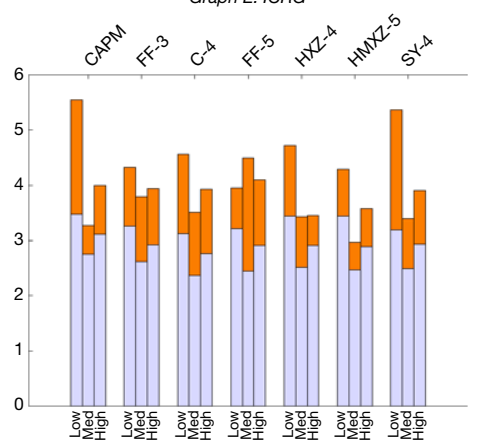

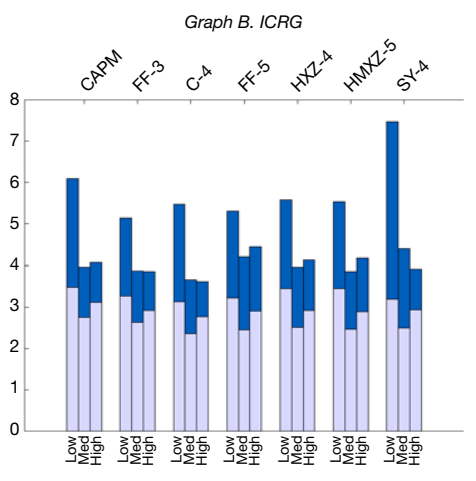
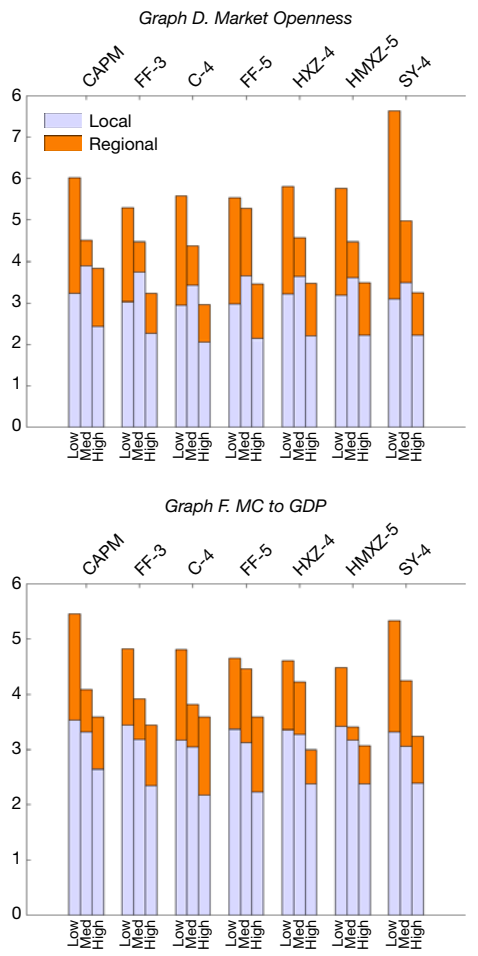
I observe a similar pattern for the variables representing political risk and relative stock market size. The alpha differences are generally largest for the countries in the low-openness and high-risk terciles, but there seems to be little difference between the countries in terciles 2 and 3 .

Thus, there seems to be no strong relation between traditional concepts of the free movement of capital and the relative performance of global and local factor models on average. If it is not capital controls and barriers to investing, how can we reconcile this with the results on the relative performance of global and local models?

It is possible that investor behavior rather than capital controls drives a wedge between the performance of global, regional, and local factor models. There are several mechanisms that could create comovement in asset returns that is mainly local. These mechanisms mainly create preferred habitats in certain markets for some of the investors (Barberis et al. (2005)), whereas their typically preferred habitat is their home country. These preferred habitats could result from capital controls and limits to foreign investments. However, there are various further possibilities. First, local investors may believe that they have information advantages in local stocks. Second, the community effects theory of DeMarzo, Kaniel and Kremer (2004) states that investors' main objective is their relative wealth compared to their peers; hence, they choose similar assets. Third, institutional investors may be evaluated relative to local benchmarks, which makes them tilt their holdings toward local assets (Basak and Pavlova (2013)). Whenever a sufficiently large investor base has a common preferred habitat, then systematic changes in these investors' preferences (e.g., risk aversion, sentiment) or liquidity demand induce common comovement in local stock returns. This comovement naturally cannot be explained by global or regional factors.

Indeed, French and Poterba (1991), Baltzer, Stolper, and Walter (2013), and Bartram, Griffin, Lim, and Ng (2015), among others, show that such investment habitats exist and are important drivers of the degree of international stock return comovement. Thus, my findings do not necessarily imply that financial markets are globally disintegrated. Local return comovement, caused by the trading behavior of local investors, and different views of global investors on local markets are probably the principal cause of the strong importance of local factors.

\section{Conclusion}

In this article, I examine the performance of various global, regional, and local asset pricing models. Using a set of 134 anomaly variables, I find that local models can price local assets best. Absolute anomaly portfolio alphas are on average 1.7 and 1.1 percentage points higher for globally and regionally diversified investors, respectively, than for purely local investors. I find that local factor models yield lower average absolute alphas for all but one of the countries in my sample. Factorspanning tests also reveal that the local factors generally create significant alphas when regressed on regional and global factor models.

The average international correlations among the anomaly strategies are moderate. Indeed, global and regional factors account for only part of these correlations. For investors, it thus appears useful to widely spread their holdings 
and simultaneously invest in anomaly strategies in various markets. This generates substantial diversification benefits.

Finally, I find that traditional concepts of financial market integration, such as, for example, capital controls or political risk, cannot account for the full scale of alpha differences between global and local factor models. Investors should thus be careful to choose, based on to what extent they are globally or regionally diversified, which type of factor models to use to evaluate investments and asset managers. If one wants to control for all sources of systematic return variation, it is important to benchmark with local factors. On the whole, alphas seem to be not only investment specific but also investor specific.

\section{Supplementary Material}

To view supplementary material for this article, please visit http://dx.doi.org/ 10.1017/S0022109021000028.

\section{References}

Amihud, Y. "Illiquidity and Stock Returns: Cross-Section and Time-Series Effects." Journal of Financial Markets, 5 (2002), 31-56.

Baltzer, M.; O. Stolper; and A. Walter. "Is Local Bias a Cross-Border Phenomenon? Evidence from Individual Investors' International Asset Allocation.” Journal of Banking and Finance, 37 (2013), 2823-2835.

Barberis, N.; A. Shleifer; and J. Wurgler. “Comovement.” Journal of Financial Economics, 75 (2005), 283-317.

Barillas, F., and J. Shanken. “Comparing Asset Pricing Models.” Journal of Finance, 73 (2018), $715-754$

Bartram, S. M.; J. M. Griffin; T.-H. Lim; and D. T. Ng. "How Important Are Foreign Ownership Linkages for International Stock Returns?” Review of Financial Studies, 28 (2015), 3036-3072.

Basak, S., and A. Pavlova. "Asset Prices and Institutional Investors." American Economic Review, 103 (2013), 1728-1758.

Brooks, R., and M. Del Negro. "Country Versus Region Effects in International Stock Returns.” Journal of Portfolio Management, 31 (2005), 67-72.

Cameron, A. C.; J. B. Gelbach; and D. L. Miller. "Robust Inference with Multiway Clustering." Journal of Business and Economic Statistics, 29 (2011), 238-249.

Carhart, M. M. "On Persistence in Mutual Fund Performance.” Journal of Finance, 52 (1997), 57-82.

Chinn, M. D., and H. Ito. "What Matters for Financial Development? Capital Controls, Institutions, and Interactions.” Journal of Development Economics, 81 (2006), 163-192.

Cooper, I.; P. Sercu; and R. Vanpée. "The Equity Home Bias Puzzle: A Survey.” Foundations and Trends in Finance, 7 (2013), 289-416.

Daniel, K.; D. Hirshleifer; and L. Sun. "Short and Long Horizon Behavioral Factors." Review of Financial Studies, 33 (2020), 1673-1736.

DeMarzo, P. M.; R. Kaniel; and I. Kremer. "Diversification as a Public Good: Community Effects in Portfolio Choice.” Journal of Finance, 59 (2004), 1677-1716.

Fama, E. F., and K. R. French. "Common Risk Factors in the Returns on Stocks and Bonds.” Journal of Financial Economics, 33 (1993), 3-56.

Fama, E. F., and K. R. French. "Multifactor Explanations of Asset Pricing Anomalies." Journal of Finance, 51 (1996), 55-84.

Fama, E. F., and K. R. French. "Value Versus Growth: The International Evidence." Journal of Finance, 53 (1998), 1975-1999.

Fama, E. F., and K. R. French. "Size, Value, and Momentum in International Stock Returns." Journal of Financial Economics, 105 (2012), 457-472.

Fama, E. F., and K. R. French. “A Five-Factor Asset Pricing Model.” Journal of Financial Economics, 116 (2015), 1-22.

Fama, E. F., and K. R. French. "International Tests of a Five-Factor Asset Pricing Model." Journal of Financial Economics, 123 (2017), 441-463. 
Fama, E. F., and K. R. French. "Choosing Factors.” Journal of Financial Economics, 128 (2018), 234-252.

French, K. R., and J. M. Poterba. "Investor Diversification and International Equity Markets.” American Economic Review, 81 (1991), 222-226.

Gibbons, M. R.; S. A. Ross; and J. Shanken. "A Test of the Efficiency of a Given Portfolio.” Econometrica, 57 (1989), 1121-1152.

Grauer, F. L.; R. H. Litzenberger; and R. E. Stehle. "Sharing Rules and Equilibrium in an International Capital Market Under Uncertainty.” Journal of Financial Economics, 3 (1976), 233-256.

Green, J.; J. R. Hand; and X. F. Zhang. "The Characteristics That Provide Independent Information about Average U.S. Monthly Stock Returns.” Review of Financial Studies, 30 (2017), 4389-4436.

Griffin, J. M. "Are the Fama and French Factors Global or Country Specific?" Review of Financial Studies, 15 (2002), 783-803.

Griffin, J. M.; P. J. Kelly; and F. Nardari. "Do Market Efficiency Measures Yield Correct Inferences? A Comparison of Developed and Emerging Markets." Review of Financial Studies, 23 (2010), 3225-3277.

Griffin, J. M., and R. M. Stulz. "International Competition and Exchange Rate Shocks: A Cross-Country Industry Analysis of Stock Returns.” Review of Financial Studies, 14 (2001), 215-241.

Harvey, C. R. "Predictable Risk and Returns in Emerging Markets." Review of Financial Studies, 8 (1995), 773-816.

Hau, H. “Global Versus Local Asset Pricing: A New Test of Market Integration.” Review of Financial Studies, 24 (2011), 3891-3940.

Heston, S. L., and K. G. Rouwenhorst. "Industry and Country Effects in International Stock Returns." Journal of Portfolio Management, 21 (1995), 53-58.

Hou, K.; G. A. Karolyi; and B.-C. Kho. "What Factors Drive Global Stock Returns?" Review of Financial Studies, 24 (2011), 2527-2574.

Hou, K.; H. Mo; C. Xue; and L. Zhang. "An Augmented $q$-Factor Model with Expected Growth." Review of Finance, 25 (2021), 1-41.

Hou, K.; C. Xue; and L. Zhang. "Digesting Anomalies: An Investment Approach.” Review of Financial Studies, 28 (2015), 650-705.

Ince, O. S., and R. B. Porter. "Individual Equity Return Data from Thomson Datastream: Handle with Care!" Journal of Financial Research, 29 (2006), 463-479.

Karolyi, G. A., and R. M. Stulz. “Are Financial Assets Priced Locally or Globally?” G. M. Constantinides; M. Harris; and R. M. Stulz, eds. "Handbook of the Economics of Finance," vol. 1, Amsterdam, Netherlands: North-Holland (2003), 975-1020.

Karolyi, G. A., and Y. Wu. "A New Partial-Segmentation Approach to Modeling International Stock Returns." Journal of Financial and Quantitative Analysis, 53 (2018), 507-546.

Lee, K.-H. "The World Price of Liquidity Risk." Journal of Financial Economics, 99 (2011), 136-161.

Lesmond, D. A. "Liquidity of Emerging Markets." Journal of Financial Economics, 77 (2005), $411-452$.

Pástor, L., and R. F. Stambaugh. "Liquidity Risk and Expected Stock Returns.” Journal of Political Economy, 111 (2003), 642-685.

Petzev, I.; A. Schrimpf; and A. F. Wagner. "Has the Pricing of Stocks Become More Global?" Working Paper, Swiss Finance Institute (2016).

Rouwenhorst, K. G. "Local Return Factors and Turnover in Emerging Stock Markets." Journal of Finance, 54 (1999), 1439-1464.

Sercu, P. "A Generalisation of the International Asset Pricing Model.” Revue de l'Association Française de Finance, 1 (1980), 91-135.

Solnik, B. H. “An Equilibrium Model of the International Capital Market.” Journal of Economic Theory, 8 (1974), 500-524.

Stambaugh, R. F., and Y. Yuan. "Mispricing Factors." Review of Financial Studies, 30 (2017), $1270-1315$.

Stulz, R. “A Model of International Asset Pricing.” Journal of Financial Economics, 9 (1981), 383-406.

Titman, S.; K. J. Wei; and F. Xie. "Market Development and the Asset Growth Effect: International Evidence." Journal of Financial and Quantitative Analysis, 48 (2013), 1405-1432.

Zhang, X. "Specification Tests of International Asset Pricing Models." Journal of International Money and Finance, 25 (2006), 275-307. 